ARTICLE

\title{
Native lattice strain induced structural earthquake in sodium layered oxide cathodes
}

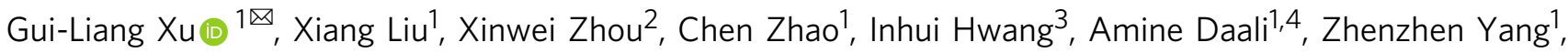 \\ Yang Ren ${ }^{3,6}$, Cheng-Jun Sun ${ }^{3}$, Zonghai Chen (10 1, Yuzi Liu (10 ${ }^{2 凶} \&$ Khalil Amine (1) ${ }^{1,5 凶}$
}

High-voltage operation is essential for the energy and power densities of battery cathode materials, but its stabilization remains a universal challenge. To date, the degradation origin has been mostly attributed to cycling-initiated structural deformation while the effect of native crystallographic defects induced during the sophisticated synthesis process has been significantly overlooked. Here, using in situ synchrotron X-ray probes and advanced transmission electron microscopy to probe the solid-state synthesis and charge/discharge process of sodium layered oxide cathodes, we reveal that quenching-induced native lattice strain plays an overwhelming role in the catastrophic capacity degradation of sodium layered cathodes, which runs counter to conventional perception-phase transition and cathode interfacial reactions. We observe that the spontaneous relaxation of native lattice strain is responsible for the structural earthquake (e.g., dislocation, stacking faults and fragmentation) of sodium layered cathodes during cycling, which is unexpectedly not regulated by the voltage window but is strongly coupled with charge/discharge temperature and rate. Our findings resolve the controversial understanding on the degradation origin of cathode materials and highlight the importance of eliminating intrinsic crystallographic defects to guarantee superior cycling stability at high voltages.

\footnotetext{
${ }^{1}$ Chemical Sciences and Engineering Division, Argonne National Laboratory, Lemont, IL 60439, USA. ${ }^{2}$ Centre for Nanoscale Materials, Argonne National Laboratory, Lemont, IL 60439, USA. ${ }^{3}$ X-ray Science Division, Argonne National Laboratory, Lemont, IL 60439, USA. ${ }^{4}$ University of Wisconsin-Milwaukee, 3200 North Cramer Street, Milwaukee, WI 53211, USA. ${ }^{5}$ Materials Science and Engineering, Stanford University, Stanford, CA 94305, USA. ${ }^{6}$ Present address: Department of Physics, University of Hong Kong, Kowloon, Hong Kong.凶email: xug@anl.gov; yuziliu@anl.gov; amine@anl.gov
} 
$\mathrm{T}$ he emerging demand for high-energy and low-cost batteries for electric vehicles and grid-scale energy storage application calls for rapid improvements in cathode materials ${ }^{1}$. Lithium/sodium-layered transition metal (TM) oxides have attracted tremendous attention as appealing cathode materials because of their high specific capacities ${ }^{2,3}$. To further increase the energy density, a prevailing approach is to push the charging voltage limit to simultaneously attain higher specific capacity and increase the average working voltage ${ }^{4}$. However, these layered cathodes undergo universal capacity drop and voltage decay during high-voltage operation ${ }^{5-7}$. Over several decades, extensive fundamental understanding and material development have been carried out to reveal the underlying failure mechanism and mitigate the structural degradation at elevated voltage.

Irreversible surface/bulk phase transition upon cycling has been reported as one of the prevalent origins for the performance degradation of layered cathodes 8,9 . Several prominent studies showed that surface reconstruction, such as layered to spinel/ rock-salt, can initiate from the cathode surface, and then gradually propagate into the bulk structure during a high-voltage charge. This eventually causes bulk fatigue of lithium layered oxide cathodes after long-term cycling ${ }^{10,11}$. Compared with their $\mathrm{Li}$ analogs that present mostly the octahedral structure through direct synthesis, sodium-layered oxide cathodes can be classified into P-type (prismatic) and O-type (octahedral), depending on the surrounding $\mathrm{Na}$ environment and the number of unique oxide layers ${ }^{12,13}$. Therefore, in general, they exhibit much more complex phase transitions such as $\mathrm{P} 2-\mathrm{O} 2^{14}, \mathrm{P} 2-\mathrm{Z}^{15}, \mathrm{P} 2-\mathrm{OP} 4{ }^{16}$, and $\mathrm{O} 3-\mathrm{P}^{\prime \prime} 3^{17}$ during high-voltage charge, leading to irreversible bulk structural changes and huge volume changes. In both cases, researchers agree that the irreversible phase transition can lead to accumulation of mechanical stress at the phase boundaries due to lattice mismatch and further intergranular/intragranular cracking of the cathode particles after prolonged cycling ${ }^{18-20}$. Therefore, tremendous efforts have been focused on suppressing the undesired phase transition through aliovalent doping ${ }^{21-25}$.

The parasitic reactions between charged cathodes and electrolytes have also been correlated with the high-voltage instability of layered oxide cathodes ${ }^{26}$. On the one hand, the common electrolytes solvents such as ethylene carbonate, diethyl carbonate, and dimethyl carbonate are thermodynamically unstable at high voltage due to their limited electrochemical stability window ${ }^{27}$. On the other hand, the charged cathodes containing highly oxidized transition metals will aggravate the decomposition of electrolytes and lead to the formation of thick cathode-electrolyte-interphase (CEI) on the cathode surface and hence sluggish $\mathrm{Li}^{+} / \mathrm{Na}^{+}$diffusion ${ }^{28}$. Mu et al. have reported that the cathode-electrolyte interfacial reaction can also trigger transition metal reduction/dissolution, heterogeneous surface reconstruction, and nanocracks ${ }^{29}$. To address these concerns, surface coating $^{30-33}$ and high-voltage electrolytes ${ }^{34-36}$ have been widely developed to enhance the high-voltage cycling stability of layered cathodes.

These valuable findings are acknowledged, but the aforementioned degradation mechanism has been mainly attributed to the dynamic structural changes (e.g., phase transition, interfacial reactions, and mechanical cracks) that nucleated and evolved during cycling. In fact, the explicit role of these structural degradations and an accurate assignment on the degradation origin remain challenging because they are intimately coupling with each other during electrochemical charge/discharge. In contrast, the effect of native structural defects often induced during the complicated synthesis process of layered oxides has been significantly overlooked. Many trial-and-error efforts have shown a strong correlation between synthetic conditions and battery performance of layered oxides, and yet the fundamental mechanism remains elusive. Moreover, cathode materials with tailor-made defects through precise synthetic control could serve as a model structure to probe their explicit role in battery performance.

Here, by using in situ synchrotron X-ray diffraction (SXRD) to probe the solid-state synthesis process of sodium-layered oxide cathodes, we intentionally synthesized a highly strained O3 $\mathrm{NaNi}_{0.4} \mathrm{Mn}_{0.4} \mathrm{Co}_{0.2} \mathrm{O}_{2}$ cathode. The electrochemical voltage window control experiments in combination with in situ SXRD, synchrotron X-ray absorption spectroscopy, and differential electrochemical mass spectrometry during charge/discharge unanimously revealed that the irreversible phase transition and cathode-electrolyte reactions are not the dominant factor for the rapid capacity fade of strained $\mathrm{NaNi}_{0.4} \mathrm{Mn}_{0.4} \mathrm{Co}_{0.2} \mathrm{O}_{2}$ cathode during cycling. Instead, using advanced transmission electron microscopy (TEM), we discovered that the native high lattice strain plays an overwhelming role in triggering the destructive structural earthquake of sodium-layered cathodes, which spontaneously relaxed due to local strain heterogeneity and led to severe breakdown/fragmentation of layered structure during prolonged cycling. We also confirmed that its relaxation process is strongly coupling with the operating temperature and charge/ discharge rate. We believe this work is the first to decouple the contribution of native lattice strain to high-voltage instability of sodium-layered cathodes and counters the conventional wisdom that phase transition and cathode-electrolyte reactions are primarily responsible for degradation.

\section{Results}

In situ synthesis study of strained $\mathrm{NaNi}_{0.4} \mathrm{Mn}_{0.4} \mathrm{Co}_{0.2} \mathrm{O}_{2}$ by SXRD. Generally, the synthesis of layered oxides involves solidstate reactions between transition metal hydroxides precursors and lithium/sodium salts by heating their mixture at a high temperature for a sufficiently long time, followed by a cooling process. Recently, researchers leveraged in situ SXRD and computational modeling to investigate the evolution of nonequilibrium kinetic intermediates and the formation of thermodynamic equilibrium phases during these processes ${ }^{37,38}$. Although these studies provide valuable guidance for the predictive synthesis of layered oxides, most of them have focused on examining the impact of structural characteristics during the heating/holding process, such as phase impurity, lattice parameter, crystallite size, $\mathrm{Li}-\mathrm{TM}$ bond length, and $\mathrm{Li}^{+} / \mathrm{Ni}^{2+}$ mixing ${ }^{39-41}$. The effect of microstrain evolution during the cooling process, especially under rapid quenching, has been largely ignored. Notably, our previous study showed that appropriate quenching could help to stabilize the metastable $\mathrm{P} 2 / \mathrm{O} 1 / \mathrm{O} 3$ intergrowth phase and tailor the electrochemical performance ${ }^{42}$. Among various phase structures in the sodium-layered oxides cathodes, the $\mathrm{O} 3$ phase represents the structure with higher $\mathrm{Na}$ content, which is different from the P2-type cathode that has a lower $\mathrm{Na}$ content and suffers from sodium deficiency problem ${ }^{13,43}$. Here, we further explored the formation process of O3 $\mathrm{NaNi}_{0.4} \mathrm{Mn}_{0.4} \mathrm{Co}_{0.2} \mathrm{O}_{2}$ cathode and revealed the effect of quenching-induced lattice strain on the crystal structures and electrochemical performance.

Figure 1a and Supplementary Fig. 1a show the 2D contour plot of in situ SXRD patterns during the formation process of $\mathrm{O} 3$ $\mathrm{NaNi}_{0.4} \mathrm{Mn}_{0.4} \mathrm{Co}_{0.2} \mathrm{O}_{2}$. The starting material was a mixture of $\mathrm{Ni}_{0.4} \mathrm{Mn}_{0.4} \mathrm{Co}_{0.2}(\mathrm{OH})_{2}$ and $5 \%$ excess mole of $\mathrm{NaOH}$. As shown more clearly by the covariance analysis and the corresponding thermalgravimetric analysis (TGA) in Supplementary Fig. 1b, c, the major reactions started to occur at around 150 and $350{ }^{\circ} \mathrm{C}$, respectively. Therefore, the formation process of $\mathrm{O} 3$ 

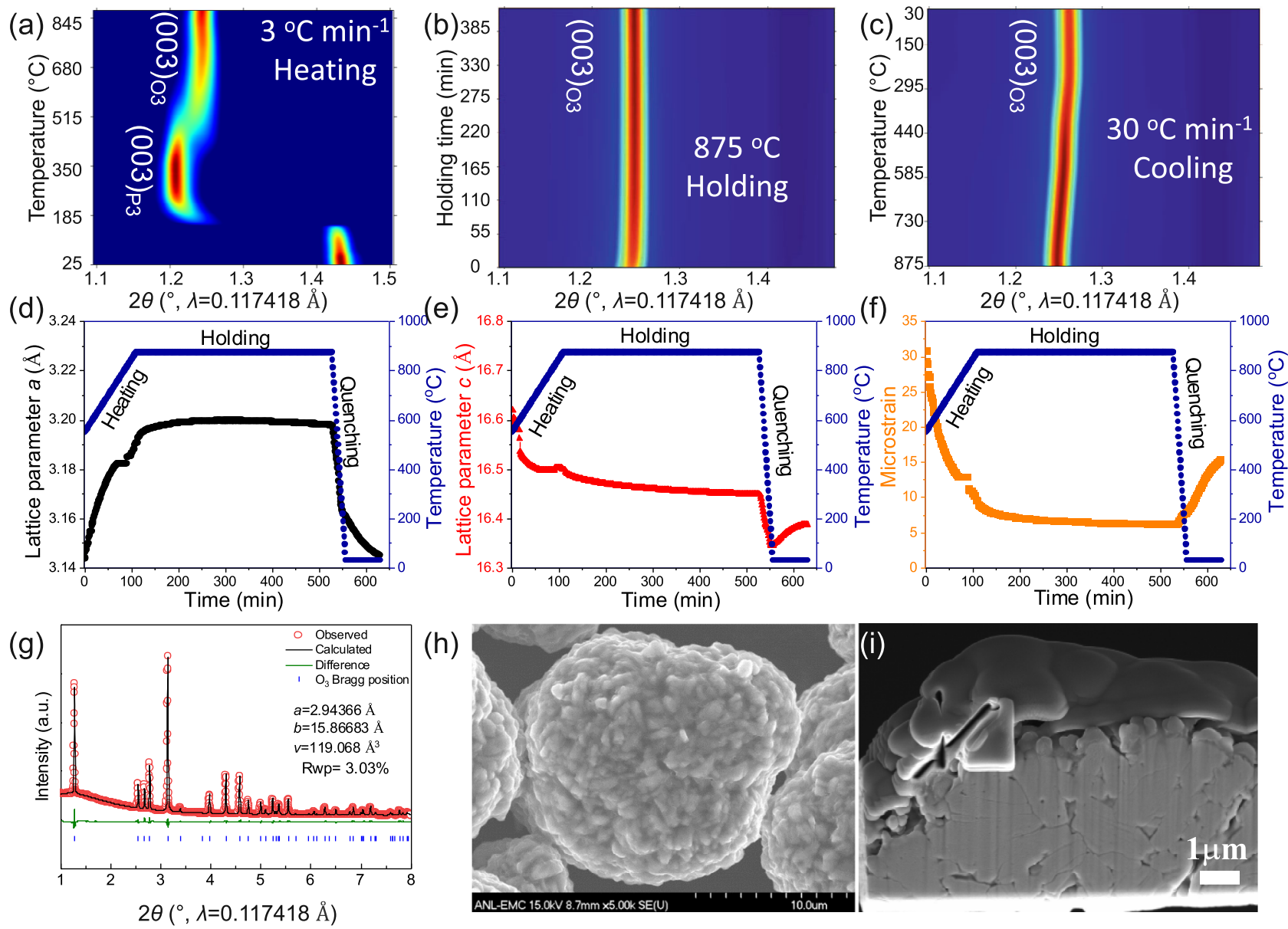

(h)
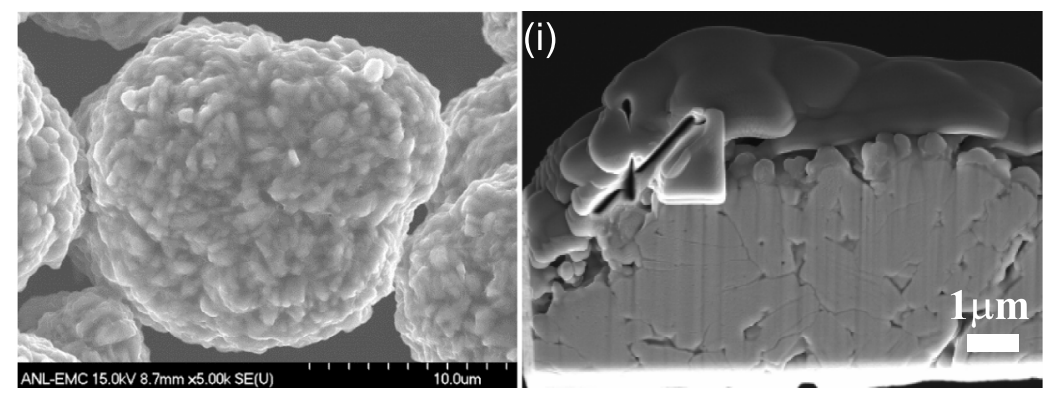

Fig. 1 Solid-state synthesis of $\mathbf{0 3} \mathbf{N a N i} \mathbf{N o . 4}_{\mathbf{0}} \mathbf{M n}_{\mathbf{0 . 4}} \mathbf{C o}_{\mathbf{0 . 2}} \mathbf{O}_{\mathbf{2}}$. 2D contour plot of in situ SXRD patterns during a heating, $\mathbf{b}$ holding, and $\mathbf{c}$ quenching process. The color in $\mathbf{a}-\mathbf{c}$ represents the intensity, with red for highest and blue for lowest. $\mathbf{d}$ Lattice parameter $a$, e lattice parameter $c$ and $\mathbf{f}$ microstrain evolution during the heating/holding/quenching process. $\mathbf{g}$ SXRD Rietveld refinement, $\mathbf{h}$ SEM image and $\mathbf{i}$ cross-section SEM image of the strained O3 $\mathrm{NaNi}_{0.4} \mathrm{Mn}_{0.4} \mathrm{Co}_{0.2} \mathrm{O}_{2}$

$\mathrm{NaNi}_{0.4} \mathrm{Mn}_{0.4} \mathrm{Co}_{0.2} \mathrm{O}_{2}$ can be classified into three regions according to their phase composition: $25-185{ }^{\circ} \mathrm{C}$ (region I, starting material), $185-500{ }^{\circ} \mathrm{C}$ (region II, intermediates), and $500-875^{\circ} \mathrm{C}$ (region III, final product). The Rietveld refinement in Supplementary Fig. 2 shows that the starting material can be indexed well as $\mathrm{Ni}(\mathrm{OH})_{2}$ and $\mathrm{NaOH}$, while the XRD pattern of the intermediate product at $350{ }^{\circ} \mathrm{C}$ is consistent with that of $\mathrm{P} 3$ $\mathrm{Na}_{0.8} \mathrm{Ni}_{0.4} \mathrm{Mn}_{0.4} \mathrm{Co}_{0.2} \mathrm{O}_{2}$. Upon further reaction beyond $500{ }^{\circ} \mathrm{C}$, the structure of the $\mathrm{O} 3$ phase started to evolve and dominate. The O3 phase remained during the holding and quenching process (Fig. 1b, c).

In order to understand subtle structural changes during the reaction process, Rietveld refinement was performed on all the measured SXRD patterns after the evolution of the $\mathrm{O} 3$ phase (i.e., $500{ }^{\circ} \mathrm{C}$ ). As shown in Fig. 1d, e, the lattice parameter $a$ was dramatically increased during heating and then gradually stabilized during the holding process; in contrast, the lattice parameter $c$ was significantly decreased during heating and then slowly decreased during the holding process. These results were attributed to the gradual transformation of P3 $(a=b=2.8479 \AA$, $c=16.6093 \AA)$ to O3 ( $a=b=2.94 \AA, c=15.923 \AA$ ) phase during heating, which exhibited distinct cell lattice parameter. In general, the structural difference between different phases can induce nonuniform lattice strain (microstrain) in the crystallite. Therefore, as shown in Fig. 1f, the decrease of $\mathrm{P} 3 / \mathrm{O} 3$ phase boundaries during the heating/holding process led to a gradual reduction of the microstrain.
We found that quenching is necessary to maintain the $\mathrm{O} 3$ phase structure during cooling. With a slow cooling under an air atmosphere, the obtained material exhibited a mixed phase of $\mathrm{P} 1 /$ P2/O3 (Supplementary Fig. 3), which might be due to the surface reconstruction induced by slow cooling ${ }^{39}$. The $\mathrm{CO}_{2}$ molecules in the air would coordinate with $\mathrm{Na}^{+}$at the solid/gas interface or attack the $\mathrm{O}$ atom of $\mathrm{NaO}_{6}$ octahedra, leading to the extraction of surficial $\mathrm{Na}^{+}$from sodium-layered oxide cathodes and hence the formation of $\mathrm{Na}_{2} \mathrm{CO}_{3}$ and Na-deficient phase, such as $\mathrm{P} 1$ and $\mathrm{P} 2^{39}$. Indeed, a clear signal of $\mathrm{Na}_{2} \mathrm{CO}_{3}$ can be observed in the $\mathrm{C} 1 \mathrm{~s}$ $\mathrm{X}$-ray photoelectron spectroscopy (XPS) spectrum of a slowcooled sample (Supplementary Fig. 4). In sharp contrast, the quenched sample exhibited high purity $\mathrm{O} 3$ phase, demonstrating a good fit with the standard O3 layered structure (Fig. 1g). The morphologies of the quenched cathode are shown in Fig. 1h, i, and exhibited characteristic conventional polycrystalline features.

Surprisingly, as shown in Fig. 1d, e, the lattice parameter $a$ and $c$ were both decreased due to the lattice shrinkage when abruptly exposed to a low temperature. During the relaxation process of the inhomogeneous thermal stress in the quenched sample, lattice parameter $a$ was significantly decreased while $c$ was drastically increased, which is similar to what occurs during the de-sodiation process of layered oxides. This indicates an increase of structural defects such as vacancies, dislocations, and stacking faults. Quenching-induced strain generation has been well known in steel manufacturing ${ }^{44}$. It has been also often used for the fabrication of battery cathode materials to control grain size, 
oxygen vacancies, and etc ${ }^{45,46}$. During quenching, a highly inhomogeneous temperature field is generated, which can result in heterogeneous thermal stresses, thus leading to residual stresses being introduced at the end of the quenching process. In our experiment, the quenching was conducted under air, which can easily induce temperature heterogeneity in the local lattice region, leading to the formation of the observed lattice strain. Therefore, the microstrain during the rapid quenching process exhibited an intense increase (Fig. 1f); while the effect of such quenchinginduced native lattice strain on the electrochemical performance of layered cathodes has not been well understood.

Electrochemical characterization of strained $\mathrm{NaNi}_{\mathbf{0 . 4}} \mathrm{Mn}_{\mathbf{0 . 4}}$ $\mathbf{C o}_{\mathbf{0 . 2}} \mathrm{O}_{2}$. The electrochemical performance of the as-prepared cathode was evaluated by using half cells with sodium metal as referenced and countered electrode. The electrolyte was $1 \mathrm{~mol} / \mathrm{L}$ $\mathrm{NaPF}_{6}$ in propylene carbonate with a 2 vol\% fluoroethylene carbonate additive. Figure $2 \mathrm{a}$ shows the first charge/discharge curves of the strained $\mathrm{O} 3-\mathrm{NaNi}_{0.4} \mathrm{Mn}_{0.4} \mathrm{Co}_{0.2} \mathrm{O}_{2}$ cathode within $2.0-4.4 \mathrm{~V}$ at $0.08 \mathrm{C}(1 \mathrm{C}=180 \mathrm{~mA} / \mathrm{g})$, which exhibited the characteristic features of the $\mathrm{O} 3$ phase with multiple-step voltage plateaus. The first charge and discharge capacity were measured to be 180.6 and $171.9 \mathrm{mAh} / \mathrm{g}$, respectively, leading to a high initial Coulombic efficiency of $95 \%$. However, upon further charge/discharge, the capacity exhibited a continuous decrease. After 100 cycles, the reversible capacity was only $54 \mathrm{mAh} / \mathrm{g}$, resulting in a low capacity retention of $30 \%$ (Fig. 1b).

Such degradation has been previously attributed to irreversible structural transformation or parasitic reactions at high voltage $^{4-6,26,29}$. Figure $2 c$ displays the in situ differential electrochemical mass spectrometry (DEMS) result of the strained $\mathrm{O} 3-\mathrm{NaNi}_{0.4} \mathrm{Mn}_{0.4} \mathrm{Co}_{0.2} \mathrm{O}_{2}$ cathode during charge/discharge within 2.0-4.4 V. Although $\mathrm{O}_{2}$ gas release has been often observed in the layered oxide cathodes when charged to high-voltage, it is also possible for the transformation of the oxygen species to $\mathrm{CO}_{2}$ because of the chemical reactions between reactive lattice oxygen and electrolytes at high-voltage ${ }^{47-49}$. Indeed, despite no evolution
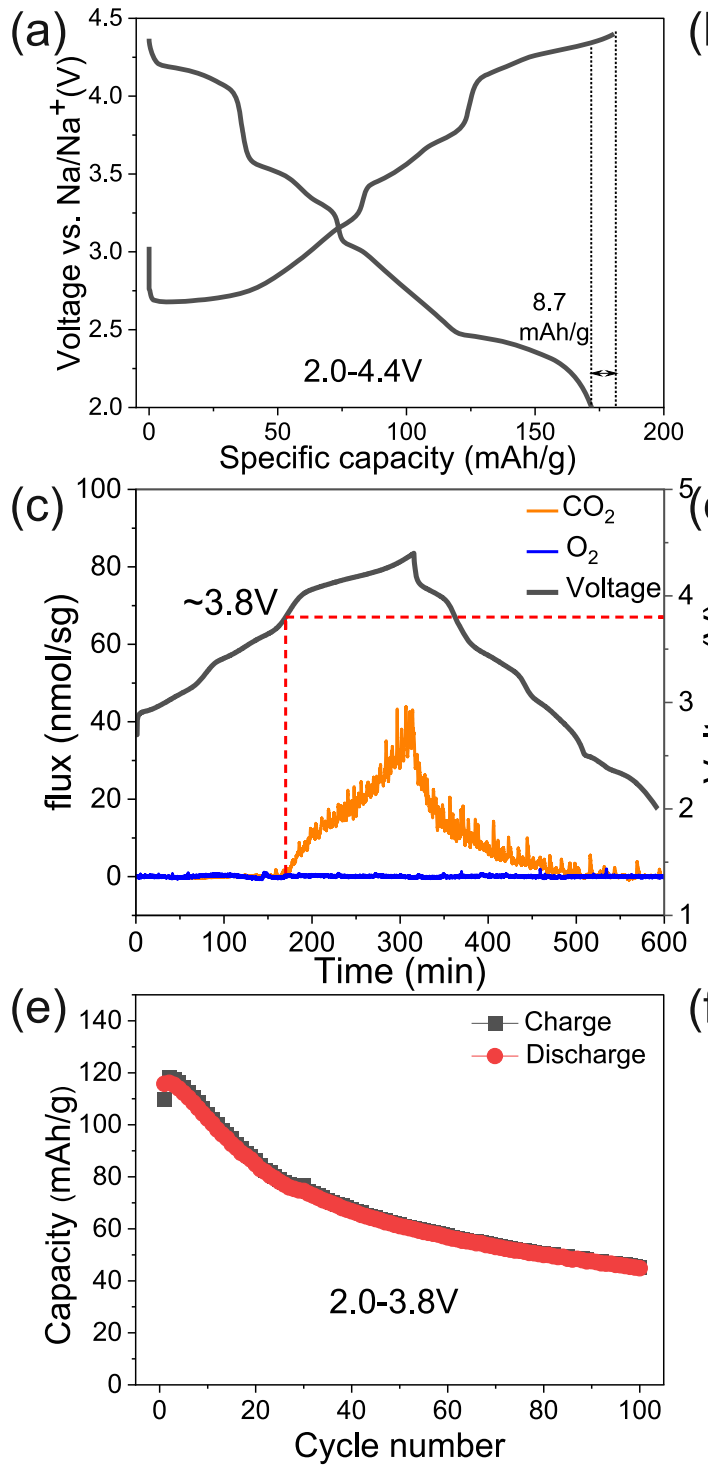

(b)

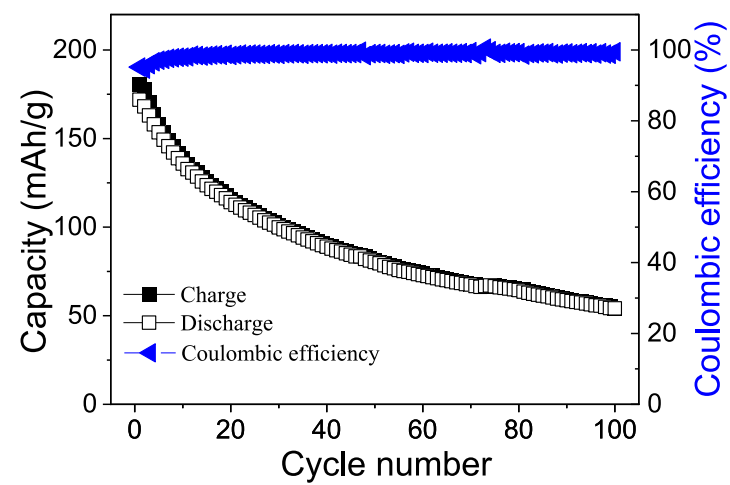

(d)

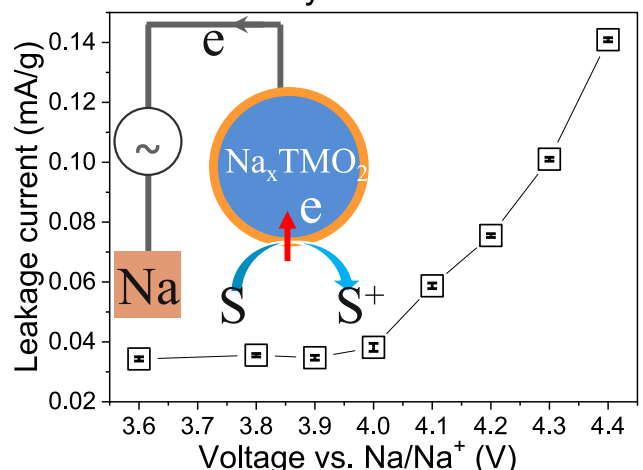

(f)

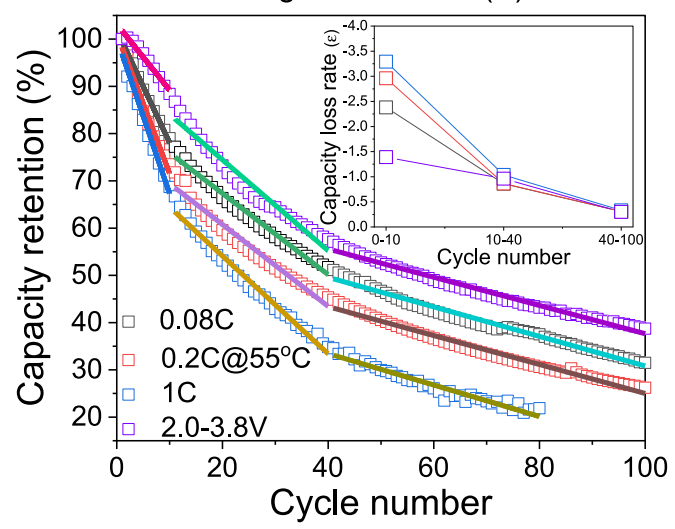

Fig. 2 Electrochemical characterization. a 1st charge/discharge curve and $\mathbf{b}$ cycling performance of strained $\mathrm{O}_{3} \mathrm{NaNi}_{0.4} \mathrm{Mn}_{0.4} \mathrm{Co}_{0.2} \mathrm{O}_{2}$ cathode within 2.0-4.4 V at 0.08C. $\mathbf{c}$ In situ DEMS and $\mathbf{d}$ parasitic reaction study of $\mathrm{O} 3 \mathrm{NaNi}_{0.4} \mathrm{Mn}_{0.4} \mathrm{Co}_{0.2} \mathrm{O}_{2}$ cathode. $\mathrm{S}$ and $\mathrm{S}^{+}$in $\mathbf{d}$ represent solvents and oxidized solvents, respectively. e Cycling performance of strained $\mathrm{O} 3 \mathrm{NaNi}_{0.4} \mathrm{Mn}_{0.4} \mathrm{Co}_{0.2} \mathrm{O}_{2}$ cathode within 2.0-3.8 $\mathrm{V}$ at $0.08 \mathrm{C}$. $\mathbf{f}$ Normalized capacity retention of $\mathrm{O} 3 \mathrm{NaNi}_{0.4} \mathrm{Mn}_{0.4} \mathrm{Co}_{0.2} \mathrm{O}_{2}$ cathode at different cycling conditions. The capacity loss rate in $\mathbf{f}$ is the slope of the linear fitting curve of the capacity retention curve. 
(a)

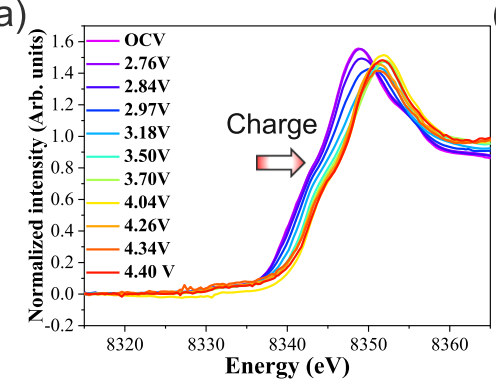

(b)

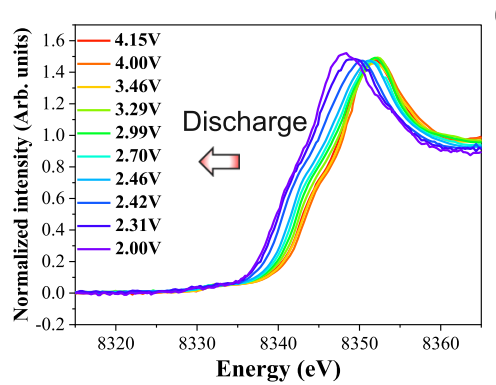

(c)

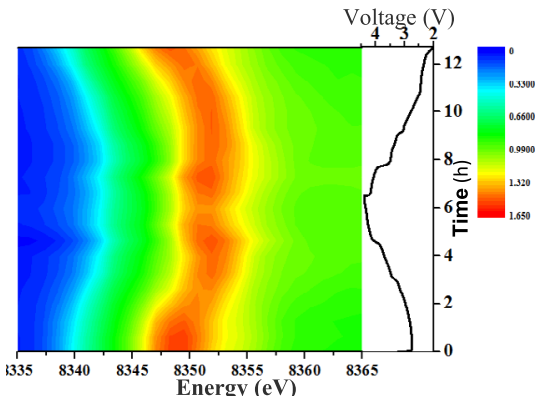

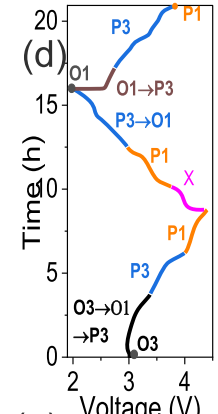
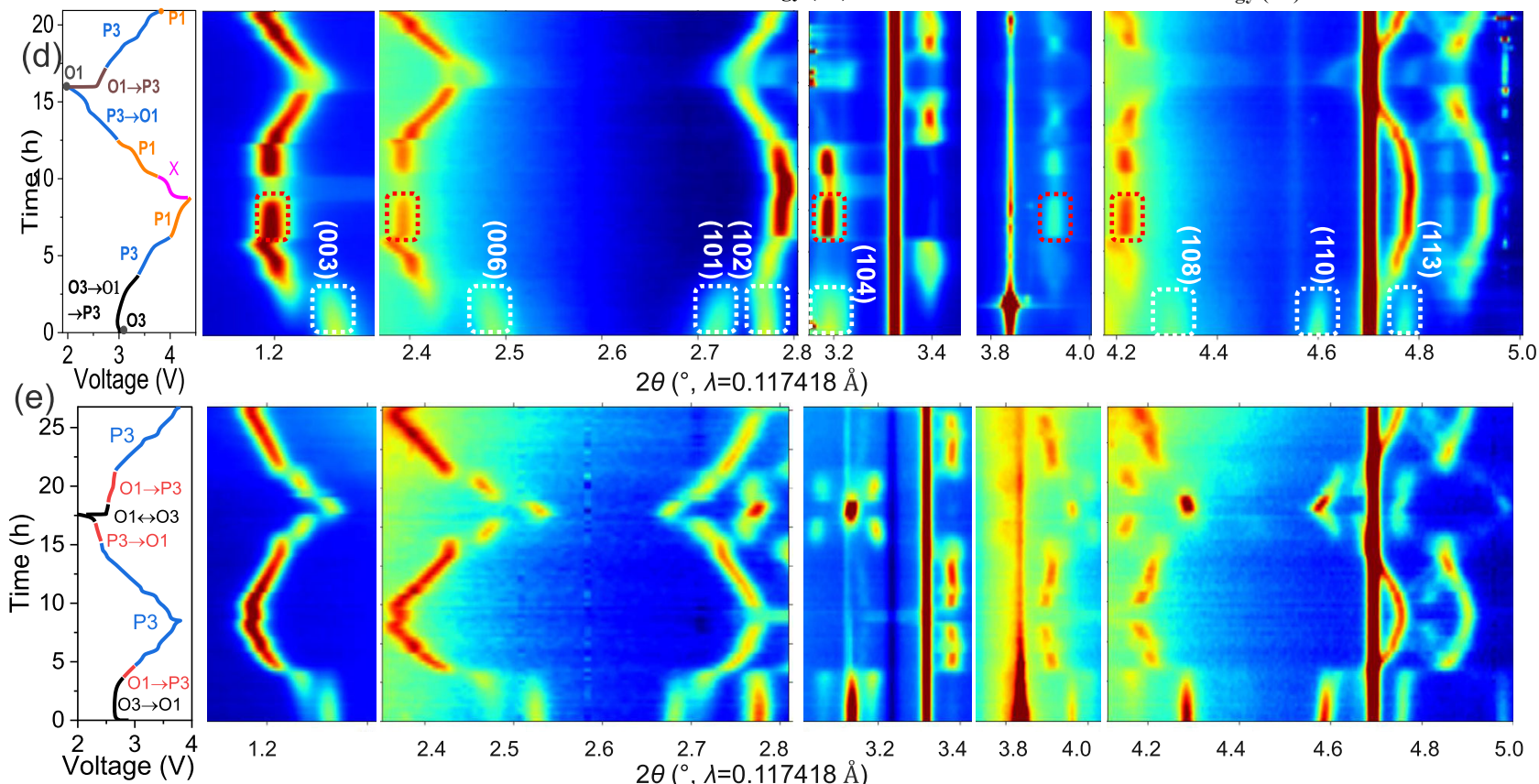
$2 \theta\left({ }^{\circ}, \lambda=0.117418 \AA\right)$
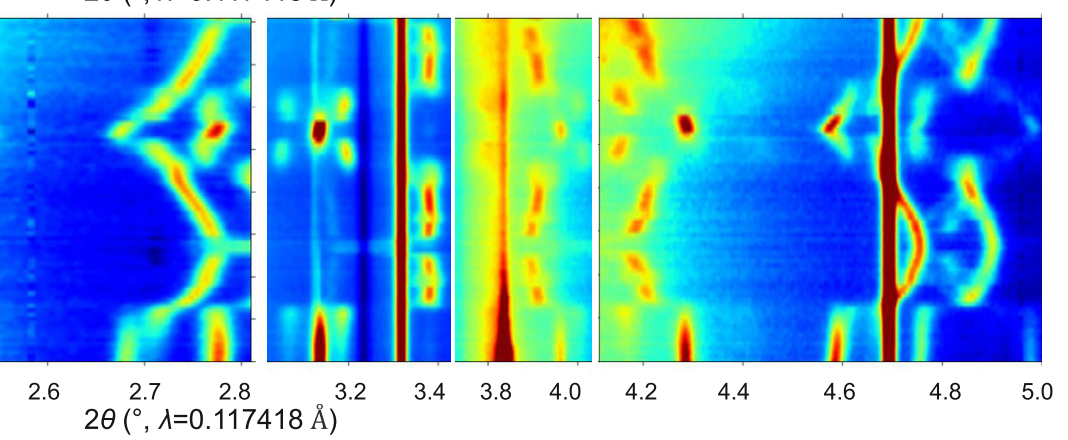

Fig. 3 In situ synchrotron characterization during charge/discharge. In situ Ni K-edge XANES of strained $\mathrm{O} 3 \mathrm{NaNi}_{0.4} \mathrm{Mn}_{0.4} \mathrm{Co}_{0.2} \mathrm{O}_{2}$ within $2.0-4.4 \mathrm{~V}:$ a during charge, $\mathbf{b}$ during discharge, and $\mathbf{c} 2 \mathrm{D}$ contour plot during charge/discharge. Voltage profiles and the corresponding 2D contour plot of in situ SXRD patterns during charge/discharge of $\mathrm{O} 3 \mathrm{NaNi}_{0.4} \mathrm{Mn}_{0.4} \mathrm{Co}_{0.2} \mathrm{O}_{2}$ cathode within $\mathbf{d}$ 2.0-4.4 $\mathrm{V}$ and e 2.0-3.8 V. The color in c-e represent the intensity, with red for highest and blue for lowest.

of $\mathrm{O}_{2}$ gas during the whole charge process, upon charging beyond $3.8 \mathrm{~V}$, a significant release of $\mathrm{CO}_{2}$ can be clearly observed. This should come from either decomposition of electrolytes or side reactions between oxygen radicals and electrolytes ${ }^{49,50}$. Consistent with this observation, the high-precision leakage current measurement results (Fig. 2d) showed that the parasitic current increased dramatically when the cut-off voltage was increased to over $4.0 \mathrm{~V}$. Therefore, in order to mitigate the capacity degradation induced by high-voltage charge, the strained O3$\mathrm{NaNi}_{0.4} \mathrm{Mn}_{0.4} \mathrm{Co}_{0.2} \mathrm{O}_{2}$ cathode was cycled between 2.0 and $3.8 \mathrm{~V}$. Surprisingly, the cycle stability was not improved by lowering the charge cut-off voltage, which contradicts results in other studies of reported sodium-layered oxide cathodes with narrow voltage window ${ }^{51}$. A capacity retention of only $38.7 \%$ was attained after 100 cycles (Fig. 2e). Moreover, the charge/discharge test of the highly strained $\mathrm{NaNi}_{0.4} \mathrm{Mn}_{0.4} \mathrm{Co}_{0.2} \mathrm{O}_{2}$ cathode at an elevated voltage or temperature demonstrated similar rapid degradation (Supplementary Fig. 5). Interestingly, the capacity fade rate (inset in Fig. 2f), which were obtained by linear fitting of the capacity retention curve, is almost the same after the first 10 cycles, regardless of voltage window, testing temperature and charge/ discharge rate, whereas they exhibited significantly different results for the first 10 cycles. The results indicate that the capacity degradation of the highly strained $\mathrm{NaNi}_{0.4} \mathrm{Mn}_{0.4} \mathrm{Co}_{0.2} \mathrm{O}_{2}$ cathode might be controlled by a specific factor, while such factor was regulated by the operating condition in the early stage of charge/ discharge.

Redox couple evolution and phase transition of strained $\mathrm{NaNi}_{0.4} \mathrm{Mn}_{0.4} \mathrm{Co}_{0.2} \mathrm{O}_{2}$ during charge/discharge. In situ $\mathrm{Ni}$ K-edge X-ray absorption near-edge spectroscopy (XANES) characterization was carried out to understand the redox couple evolution of the highly strained $\mathrm{NaNi}_{0.4} \mathrm{Mn}_{0.4} \mathrm{Co}_{0.2} \mathrm{O}_{2}$ cathode during charge/discharge within 2.0-4.4 $\mathrm{V}$, which can provide the oxidation state changes of $\mathrm{Ni}$ element during battery operation. As shown in Fig. 3a, b, the Ni K-edge shifted to high-energy upon extraction of $\mathrm{Na}^{+}$due to the oxidation of $\mathrm{Ni}^{2+}$ to $\mathrm{Ni}^{3+} / \mathrm{Ni}^{4+}$ during charge, while it shifted back to lower energy during discharge due to the reduction of $\mathrm{Ni}^{3+} / \mathrm{Ni}^{4+}$ to $\mathrm{Ni}^{2+42}$. In general, as shown in the $2 \mathrm{D}$ contour plot of Ni K-edge XANES throughout the whole charge/discharge process (Fig. $3 \mathrm{c}$ ), the Ni undergoes a highly reversible Ni oxidation/reduction during charge/discharge within 2.0-4.4 V. Even after cycling for 10 cycles that have triggered severe capacity degradation in the strained $\mathrm{O} 3$ cathode, $\mathrm{Ni}$ still exhibits reversible redox reactions (Supplementary Fig. 6a), which cannot explain the severe capacity loss of strained $\mathrm{NaNi}_{0.4} \mathrm{Mn}_{0.4} \mathrm{Co}_{0.2} \mathrm{O}_{2}$ cathode reported here (Fig. 2b). The redox reaction behavior of $\mathrm{Co}$ and $\mathrm{Mn}$ in the $\mathrm{O} 3$ strained $\mathrm{NaNi}_{0.4} \mathrm{Mn}_{0.4} \mathrm{Co}_{0.2} \mathrm{O}_{2}$ cathode were also explored and both 
showed reversible transformation during cycling within $2.0-4.4 \mathrm{~V}$ (Supplementary Fig. 6b, c), indicating that the observed capacity degradation is not from the cycling-induced structural transformation.

Therefore, we further performed in situ SXRD to reveal the phase transition of strained $\mathrm{NaNi}_{0.4} \mathrm{Mn}_{0.4} \mathrm{Co}_{0.2} \mathrm{O}_{2}$ cathode with a controlled voltage window. Figure $3 \mathrm{~d}$ shows the $2 \mathrm{D}$ contour plot of in situ SXRD patterns during charge/discharge within $2.0-4.4 \mathrm{~V}$, in accompaniment with the corresponding voltage curve and phase transition process. As shown, the electrode before charge/discharge can be well indexed using the $\mathrm{O} 3$ phase. Upon charge, the (003) and (006) peaks shifted toward lower angles, which indicated an expansion of the $c$ lattice parameter due to the increased oxygen electrostatic repulsion between oxygen layers induced by the removal of $\mathrm{Na}^{+}$. Meanwhile, the (101), (102), (110), and (113) peaks moved towards higher angles during charge, corresponding to shrinkage of $a$ lattice parameter due to the oxidation of TM. In addition, the intensity of the $\mathrm{O} 3$ phase gradually decreased, while the peaks of the $\mathrm{O} 1$ phase started to appear. Upon further charge, the $\mathrm{O} 1$ phase was then transformed into the $\mathrm{P} 3$ phase starting at $3.37 \mathrm{~V}$. At the long plateau beyond $4.0 \mathrm{~V}$, the structure of the $\mathrm{P} 1$ phase started to dominate the charged product. At the end of the charge process, an unknown $\mathrm{X}$ phase with low $\mathrm{Na}$ content and crystallinity was formed. Therefore, the phase transformation of strained $\mathrm{NaNi}_{0.4} \mathrm{Mn}_{0.4^{-}}$ $\mathrm{Co}_{0.2} \mathrm{O}_{2}$ cathode during high-voltage charge can be described as $\mathrm{O} 3 \rightarrow \mathrm{O} 1 \rightarrow \mathrm{P} 3 \rightarrow \mathrm{P} 1 \rightarrow \mathrm{X}$, which is similar to the previously reported $\mathrm{O} 3$ sodium-layered cathode when charged to high voltage $^{52}$. During the discharge process, the phase transformation process reversed. However, at the beginning of the discharge process, the XRD intensities of $(00 l)$ peaks are very weak and broad, indicating severe lattice strain at the $c$ axis direction that prevents the re-insertion of $\mathrm{Na}^{+}$. Moreover, as evidenced by the disappearance of O3 (003), (006), (101), (108) and (110) peaks of the $\mathrm{O} 3$ phase, the $\mathrm{O} 1$ phase (rather than the original $\mathrm{O} 3$ phase) dominated the fully discharged electrode, indicating an irreversible phase transition during high-voltage cycling.
In sharp contrast with that charge/discharge within $2.0-4.4 \mathrm{~V}$, the highly strained $\mathrm{NaNi}_{0.4} \mathrm{Mn}_{0.4} \mathrm{Co}_{0.2} \mathrm{O}_{2}$ cathode exhibited a highly reversible phase transformation of $\mathrm{O} 3 \leftrightarrow \mathrm{O} 1 \leftrightarrow \mathrm{P} 3$ with a lower charge cut-off voltage of $3.8 \mathrm{~V}$. As clearly shown in Fig. 3e, the in situ SXRD patterns during the whole charge/discharge process presented a highly symmetric feature, and all the peaks of O3 phase were fully recovered at the end of the discharge process. Such a reversible phase transition during charge/discharge of layered oxide cathodes is often considered favorable for the stabilization of their cycle performance ${ }^{53}$. However, we illustrate that this is not the case of the highly strained $\mathrm{NaNi}_{0.4} \mathrm{Mn}_{0.4^{-}}$ $\mathrm{Co}_{0.2} \mathrm{O}_{2}$ cathode (Fig. 2e). Thus, its degradation origin remains elusive.

Native lattice strain-induced structural earthquake in $\mathrm{NaNi}_{\mathbf{0 . 4}} \mathbf{M n}_{\mathbf{0 . 4}} \mathrm{Co}_{\mathbf{0 . 2}} \mathrm{O}_{\mathbf{2}}$. Inspired by the in situ SXRD results during the quenching process, we further examined the crystallographic structure of the highly strained $\mathrm{NaNi}_{0.4} \mathrm{Mn}_{0.4} \mathrm{Co}_{0.2} \mathrm{O}_{2}$ cathode at the atomistic level by using advanced TEM. Figure $4 \mathrm{a}$, $\mathrm{b}$ shows the low and high magnification TEM image of the pristine $\mathrm{NaNi}_{0.4} \mathrm{Mn}_{0.4} \mathrm{Co}_{0.2} \mathrm{O}_{2}$ particle, respectively. Unlike the slow-cooling synthesized $\mathrm{O} 3$ sodium oxide cathodes that showed smooth surface and well-aligned lattice fringes ${ }^{54}$, the quenched cathode exhibited a highly rough surface and fluctuated strain contours in a large area. Interestingly, we do not observe an obvious composition heterogeneity across the strained region (Supplementary Fig. 7). These structural features have been mostly observed in the cycled cathodes materials ${ }^{1,55}$, but barely in the pristine cathodes. The HRTEM image in Fig. 4c illustrates that the $d$-spacing along the $c$ axis direction is about $0.549 \mathrm{~nm}$, which is stretched by about $3.58 \%$ compared to that of the standard $\mathrm{O} 3$ phase $(0.530 \mathrm{~nm})$. A closer examination (inset of Fig. 4c) clearly shows the existence of severe lattice distortion along the $c$ axis direction, in which we can see the curved lattice fringe and overlap of TM atoms and $\mathrm{Na}$ atoms. Such lattice distortion might accelerate cation mixing or cation migration during cycling, leading to undesired structural evolution and
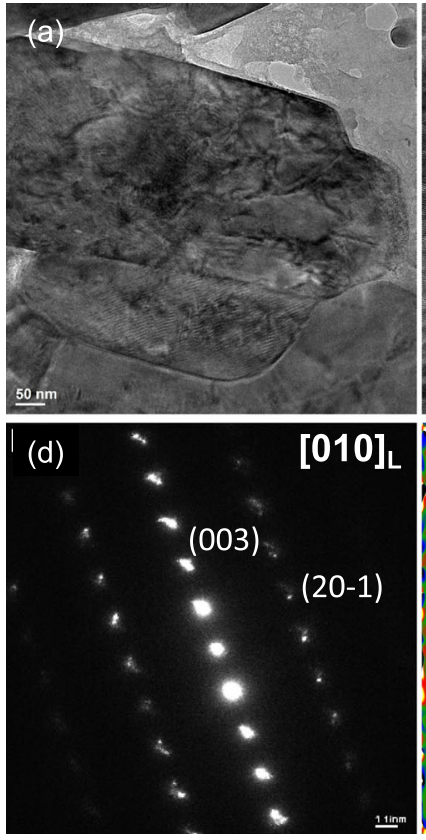
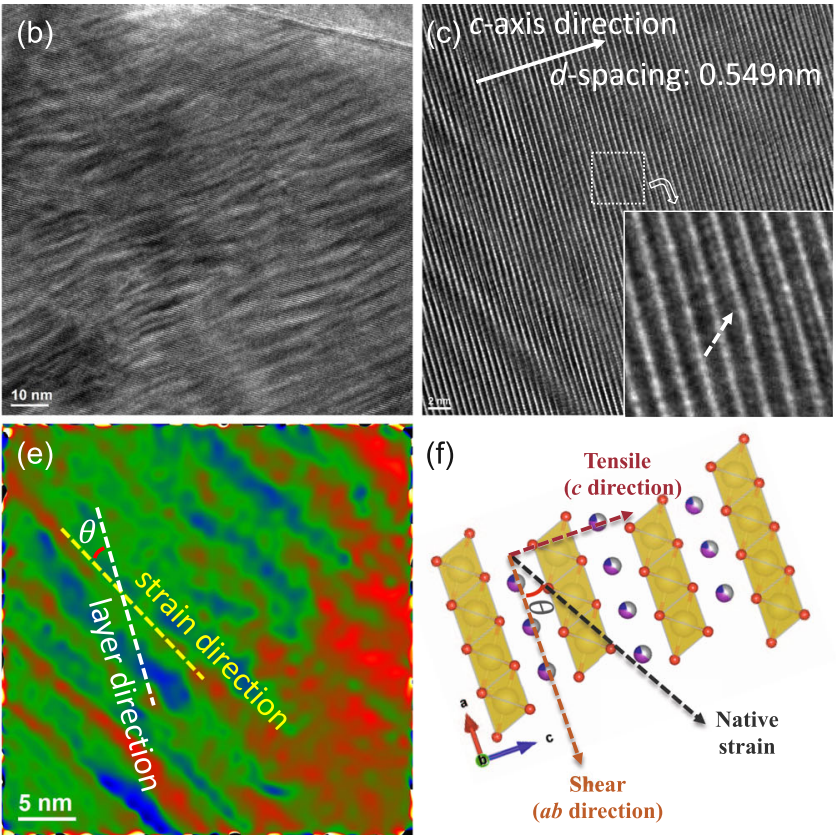

Fig. 4 TEM characterization of pristine $\mathbf{0 3} \mathbf{N a N i}_{\mathbf{0 . 4}} \mathbf{M n}_{\mathbf{0 . 4}} \mathbf{C o}_{\mathbf{0 . 2}} \mathbf{O}_{\mathbf{2}}$. a Low and $\mathbf{b}$ high magnification, $\mathbf{c}$ high-resolution bright-field TEM image, $\mathbf{d}$ SAED pattern, e GPA analysis and $\mathbf{f}$ atomic structural model of the strained $\mathrm{O} 3 \mathrm{NaNi}_{0.4} \mathrm{Mn}_{0.4} \mathrm{Co}_{0.2} \mathrm{O}_{2}$. Inset in $\mathbf{c}$ is the zoomed-in view of the region marked by a white square. The color in $\mathbf{c}$ represents the intensity, with red for highest and blue for lowest. $\theta$ is the angle between layered direction and strain direction. The yellow, red, blue, gray, and purple spheres in $\mathbf{f}$ represent $\mathrm{Na}, \mathrm{O}, \mathrm{Ni}, \mathrm{Co}$, and $\mathrm{Mn}$ atoms, respectively. 
hence capacity/voltage fade ${ }^{56-59}$. In addition, the $d$-spacing along the $a b$ axis exhibited an inhomogeneous distribution (Supplementary Fig. 8). The selected area electron diffraction (SAED) pattern in Fig. $4 \mathrm{~d}$ is in good agreement with the [010] projection of layered $\mathrm{O} 3$ cathode, but exhibits obvious spot splitting. All the aforementioned structural features are due to the native high lattice strain induced during the quenching process, leading to the highly metastable nature of strained $\mathrm{O} 3$ cathode. The corresponding geometric phase analysis (GPA) of Fig. 4c provided the direct strain distribution of the $\mathrm{NaNi}_{0.4} \mathrm{Mn}_{0.4} \mathrm{Co}_{0.2} \mathrm{O}_{2}$ cathode, which showed an angle between layered direction and strain direction (Fig. 4e). Such native lattice strain can be thus separated into tensile stress along the $c$ axis direction that tends to stretch the lattice, and shear stress along the $a b$ axis direction that will compress the lattice (Fig. 4f). Upon extraction of $\mathrm{Na}^{+}$, such metastable structure tends to undergo spontaneous strain relaxation and cause significant structural degradation as revealed below.

Figure $5 \mathrm{a}$ shows the bright-field TEM image of strained $\mathrm{NaNi}_{0.4} \mathrm{Mn}_{0.4} \mathrm{Co}_{0.2} \mathrm{O}_{2}$ cathode after charge/discharge within $2.0-4.4 \mathrm{~V}$ at $0.08 \mathrm{C}$ for 100 cycles. Compared to the pristine one (Fig. 4b), a large portion of the native lattice strain was relaxed since the strain contours disappeared. HRTEM image (Fig. 5b) and the zoomed-in view (Fig. 5c) shows that there are numerous stacking faults and dislocations as a catastrophic consequence of strain relaxation. In particular, we can clearly see the bending of lattice (yellow dashed lines in Fig. 5c) parallel to the layered direction due to the shear stress along the $a b$ axis. Moreover, the tensile stress along the $c$ axis direction led to the evolution of lattice dislocations and stacking faults. As a result, it will be difficult to re-insert $\mathrm{Na}^{+}$into the $\mathrm{Na}$ layer because of the crossover of TM cations that might occupy the $\mathrm{Na}$ sites and damage layered structure, implied by the disappearance of $(00 l)$ peaks in the in situ SXRD patterns at the beginning of the discharge process (Fig. 3d). Hence, the material suffered from a dramatic capacity loss.

On the other hand, by examining the strain-relaxed region in Fig. 5a (marked by a white rectangle), it was found that the observed gaps between two layered planes are not empty; they are composed by low-crystalline fragmented domains (Supplementary Fig. 9). This conclusion is further supported by the STEMEDS elemental mapping of cycled cathode in Supplementary Figs. 10 and 11, in which the electrolytes (signal element of P) cannot penetrate into the outlined gaps while the signal of TM, such as $\mathrm{Ni}$, can be clearly observed. Figure $5 \mathrm{~d}$ clearly showed that a layer of NiO-like rock-salt structure with (111) plane was formed at the tip of the premature crack region. As reported by Wang and co-workers, the (111) plane of rock-salt structure is energetically and structurally favorable, and has a high tolerance against compression strain ${ }^{60}$. However, the native high lattice strain in the quenched cathode significantly exceeds both tensile and compression limit of the rock-salt phase, thus leading to the formation of rock-salt fragments with different orientations (Fig. 5e and supplementary Fig. 9). In contrast, in the strain-
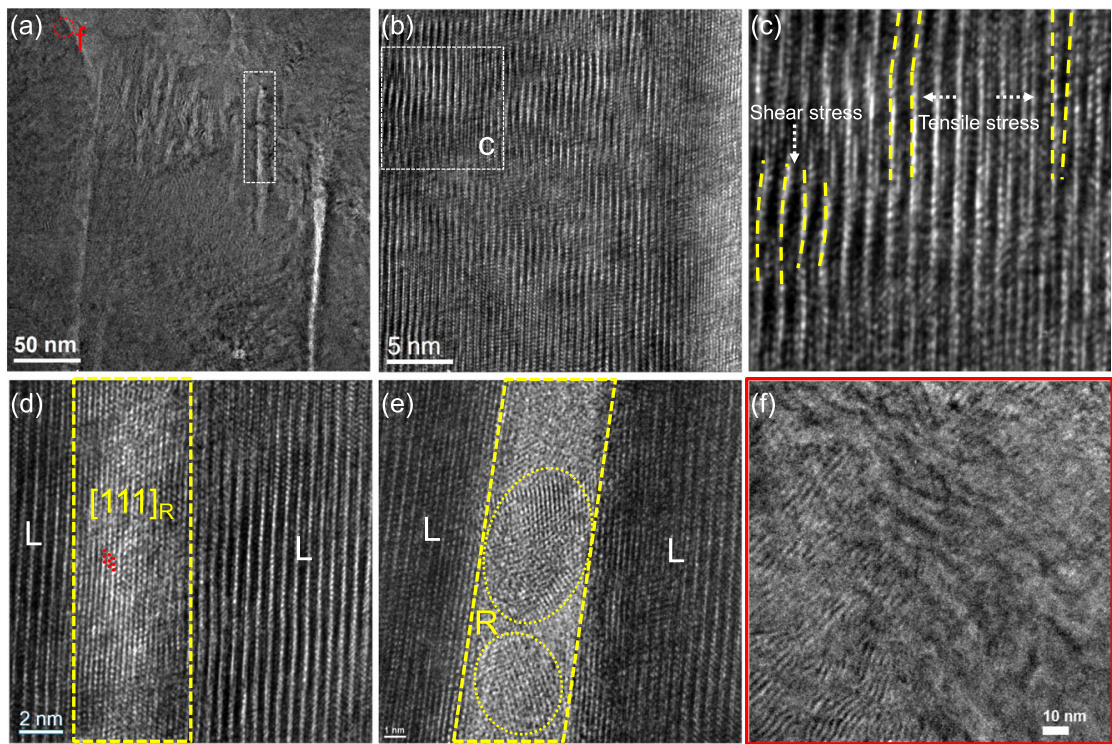

(g)
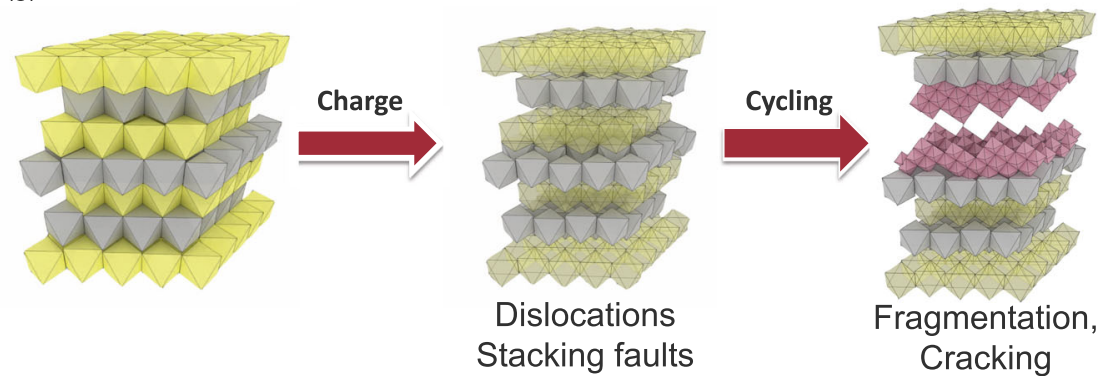

Fig. 5 TEM characterization on cycled $03 \mathbf{N a N i}_{\mathbf{0 . 4}} \mathbf{M n}_{\mathbf{0 . 4}} \mathbf{C O}_{\mathbf{0 . 2}} \mathbf{O}_{\mathbf{2}}$ cathode particle (2.0-4.4 $\mathbf{V}$ for $\mathbf{1 0 0}$ cycles). a Low and b high magnification TEM image. c Zoomed-in view of the dashed square area in $\mathbf{b}$. d, e Zoomed-in views of the dashed rectangle area in $\mathbf{a}$. $\mathbf{f}$ Zoomed-in view of dot-circle area in $\mathbf{a}$. $\mathbf{g}$ Schematic illustration of the structural earthquake during cycling of strained $\mathrm{O} 3 \mathrm{NaNi}_{0.4} \mathrm{Mn}_{0.4} \mathrm{Co}_{0.2} \mathrm{O}_{2}$ cathode. $\mathrm{R}$ and $\mathrm{L}$ in $\mathbf{d}$, e represents rock-salt and layered structure, respectively. Yellow and gray octahedra represents $\mathrm{NaO}_{6}$ and $\mathrm{TMO}_{6}$ of a layered structure, respectively. Purple octahedra means rocksalt structure. 

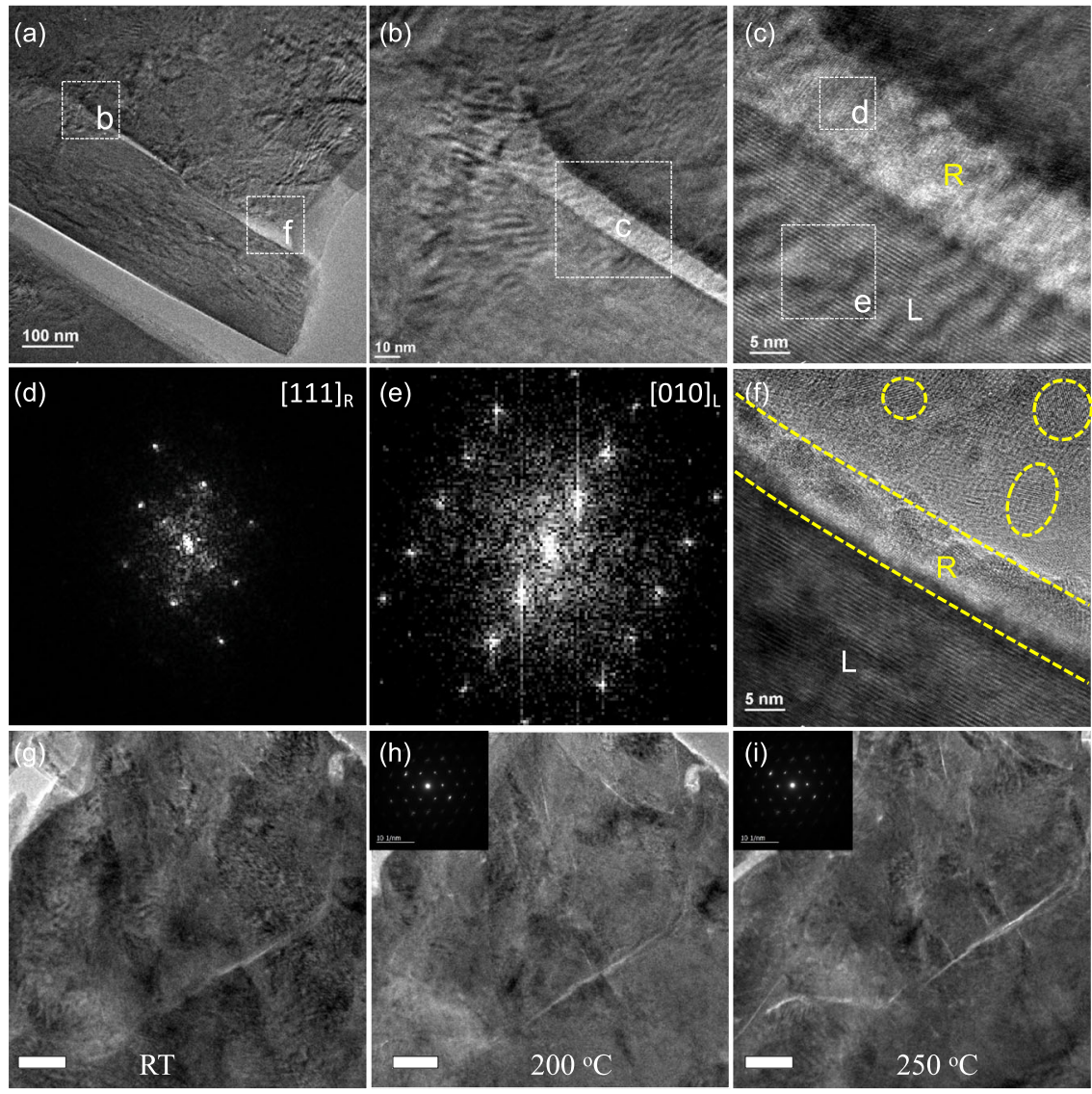

Fig. 6 TEM characterization on cycled $03 \mathrm{NaNi}_{0.4} \mathbf{M n}_{\mathbf{0 . 4}} \mathrm{Co}_{\mathbf{0 . 2}} \mathbf{O}_{\mathbf{2}}$ (2.0-3.8 $\mathrm{V}$ for $\mathbf{1 0}$ cycles). a Low magnification TEM image. b Zoomed-in view of the dashed square area in $\mathbf{a}$. c Zoomed-in view of the dashed square area in $\mathbf{b}$. d, e Corresponding FFT patterns of the dashed square area in $\mathbf{c}$. $\mathbf{f} H R T E M$ image of the dashed square area $\mathbf{f}$ in $\mathbf{a}$. In situ TEM images of $3.8 \mathrm{~V}$-charged $\mathrm{O} 3 \mathrm{NaNi}_{0.4} \mathrm{Mn}_{0.4} \mathrm{Co}_{0.2} \mathrm{O}_{2}$ cathode during heating: $\mathbf{g}$ at room temperature; $\mathbf{h}$ at 200 ${ }^{\circ} \mathrm{C}$ and $\mathbf{i}$ at $250{ }^{\circ} \mathrm{C}$. Insets of $\mathbf{h}$ and $\mathbf{i}$ are the corresponding SAED patterns. $\mathrm{R}$ and $\mathrm{L}$ represents the rock-salt and layered structure, respectively.

unrelaxed region (blue circle in Fig. 5a), the curved lattice fringes were preserved, and no formation of cracks or premature cracks can be observed even at the grain boundaries that have long been considered as the preferred crack-initiating sites (Fig. 5f). The structure evolution of the highly strained $\mathrm{NaNi}_{0.4} \mathrm{Mn}_{0.4} \mathrm{Co}_{0.2} \mathrm{O}_{2}$ cathode during charge/discharge is schematically illustrated in Fig. $5 \mathrm{~g}$, which is very similar to the earthquake process. The curved lattice fringes of strained layered oxide cathodes introduced by quenching during material synthesis are similar to the curved stratum of the earth due to the stored elastic strain energy. The extraction/insertion of $\mathrm{Na}^{+}$plays a similar role to plate motion, which leads to the release of stored energy (native strain) in a way of cracking, displacement, and dip/strike faulting that also occurred during the structural degradation of layered cathodes.

Therefore, such strain relaxation does not necessitate a highvoltage charge but should be more related to local strain distribution. Figure 6 shows the structures of cycled strained cathode during charge/discharge with a lower cut-off voltage of $3.8 \mathrm{~V}$ for 10 cycles. As shown in Fig. 6a, two strain-relaxed regions can be observed, with one on the surface (marked by dashed square $f$ ) and the other one in the interior of the particle (marked by dashed square b). The results are contradictory to the prevailing surface-to-bulk phase transformation mode for layered cathodes, which believed that the degradation was initiated from the surface ${ }^{61,62}$. Although our investigated system is based on a highly strained material, which is different from most of the previously investigated materials, the synthesis of layered oxide cathodes generally involves the sophisticated process, which can actually induce many different kinds of native structural defects, especially during the large-scale manufacturing process that could easily suffer from temperature heterogeneity. Indeed, boundaries $^{63-66}$, nanopores ${ }^{67}$, and dislocations ${ }^{68}$ have been observed in several lithium-layered oxide cathodes, of which their distribution could act as the starting points of structural degradation, which however does not always initiate from the surface.

The zoomed-in view of square b in Fig. 6a clearly reveals that the strain relaxation was terminated exactly at the end of the strain-unrelaxed region (Fig. 6b). Moreover, Fig. 6c clearly shows that the strain-relaxed region $(\sim 10 \mathrm{~nm})$ exhibited rock-salt structure (square d), while the layered structures remained in the strain-unrelaxed region (square e). These are further supported by the corresponding Fast Fourier Transform (FFT) patterns in Fig. 6d, e, which are in good agreement with that projected from [111] direction of rock-salt phase and [010] direction of layered phase, respectively. In another strain-relaxed region (Fig. 6f, zoomed-in view of square $f$ in Fig. 6a), we also observed the formation of rock-salt domains with different orientations, which are similar to those that occurred during high-voltage charge (Fig. 5d, e). Therefore, the charge cut-off voltage does not play a critical role in activating the strain relaxation, which can explain the similar capacity fade behavior of strained $\mathrm{NaNi}_{0.4} \mathrm{Mn}_{0.4} \mathrm{Co}_{0.2} \mathrm{O}_{2}$ cathode during cycling with different cut-off voltage.

To directly stimulate the strain relaxation process and the associated structural transformation during charge/discharge, we further conducted in situ TEM observation during heating of 
charged $(3.8 \mathrm{~V})$ strained $\mathrm{NaNi}_{0.4} \mathrm{Mn}_{0.4} \mathrm{Co}_{0.2} \mathrm{O}_{2}$ cathode. Before in situ heating, a high distribution of inhomogeneous lattice strain as the contours and intragranular gaps can be clearly observed (Fig. 6g). After heating to high temperature, the preexisting gaps propagated in accompaniment with the formation of high-density new nanogaps. In particular, we can see that the gaps were widened or appeared starting from the regions that exhibit higher lattice strain (Fig. 6h, i). Nevertheless, the layered structure of the strained $\mathrm{NaNi}_{0.4} \mathrm{Mn}_{0.4} \mathrm{Co}_{0.2} \mathrm{O}_{2}$ cathode was well preserved even after heating to $250^{\circ} \mathrm{C}$, as evidenced by the corresponding SAED patterns in the inset. The results again indicate that layered to rock-salt phase transformation is not the dominant factor to trigger the formation of cracks, but might be a consequence of strain relaxation.

\section{Discussion}

The aforementioned results have clearly emphasized the critical role of native lattice strain in initiating the structural earthquake of sodium-layered oxide cathodes, which can lead to extremely fast capacity degradation. It has clearly distinguished native lattice strain from other common factors such as phase transition and cathode/electrolytes parasitic reactions. Although it is well known that the lattice strain could be also generated due to lattice mismatch and reaction heterogeneity from the aforementioned structural deformation during cycling, it generally takes a long time to break the threshold value and cause an abrupt capacity degradation. Instead, the native lattice strain induced during the synthesis of sodium-layered oxides could significantly exceed the threshold limits, and hence dominate their failure process. The results indicate that it is very important to eliminate the native lattice strain by fine-tuning the synthetic conditions and also to minimize the strain generation during cycling by rational structure tailoring. The concentration and distribution of these lattice strains depend on the quenching conditions (e.g., medium, cooling rate, etc.) Therefore, the selection of quenching medium (e.g., liquid $\mathrm{N}_{2}$, fluid, etc.) and cooling rate/environment that can ensure a homogeneous thermal distribution and transformation could help to alleviate the lattice strain. Moreover, inspired by steel manufacturing, optimization of post-annealing procedures could also help to eliminate these intrinsic lattice strains.

Although the strain relaxation process is not regulated by the voltage window, it is critical to understand the potential factors that can regulate this process. Charge/discharge temperature and rate are two common factors that can dramatically affect the cycle stability of cathode materials. Therefore, we further investigated their influence on the strain relaxation process. Figure 7 compares the structures of cycled strained $\mathrm{NaNi}_{0.4} \mathrm{Mn}_{0.4} \mathrm{Co}_{0.2} \mathrm{O}_{2}$ cathode after 100 cycles of charge/discharge under different conditions. Under a low charge/discharge rate of $0.08 \mathrm{C}$ at room temperature, the strain relaxation was relatively smooth, leading to the formation of a straight incision (marked by white rectangles in Fig. 7a, b). This is because the extraction/insertion of $\mathrm{Na}^{+}$is proceeding in a very slow manner, which can thus minimize the effect of stress heterogeneity. This is similar to common phenomena, such as smooth plate motion or tearing wrinkle paper in a slow manner. Again, we can see the tip of the gap was terminated at the end of the strain-unrelaxed region. With elevated
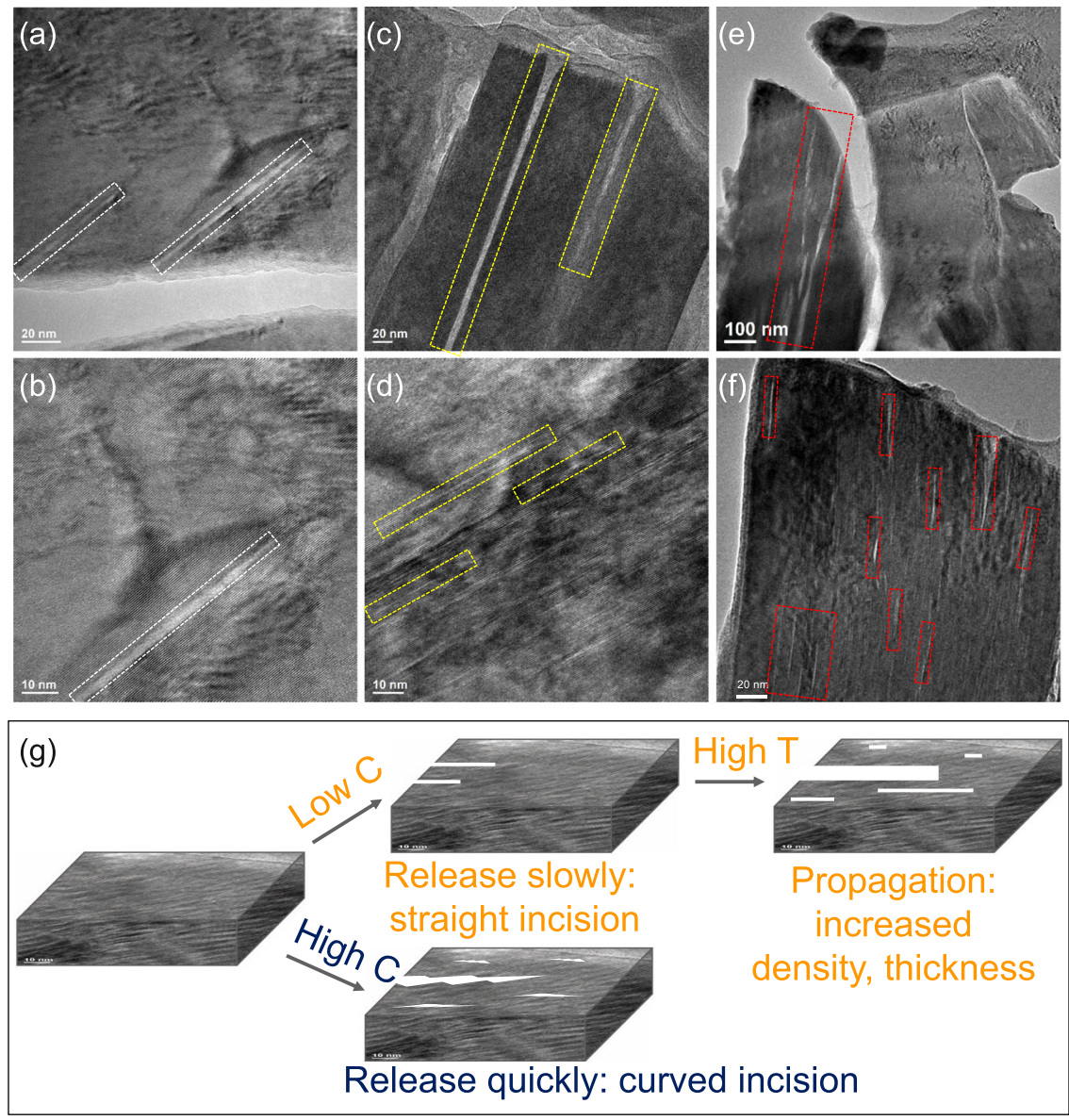

Fig. 7 Strain relaxation under different conditions. Low and high magnification TEM images of $\mathrm{O} 3 \mathrm{NaNi}_{0.4} \mathrm{Mn}_{0.4} \mathrm{Co}_{0.2} \mathrm{O}_{2}$ cathode after 100 cycles within 2.0-4.4 V at different conditions: a, b $0.08 \mathrm{C}$ under room temperature; $\mathbf{c}, \mathbf{d} 0.2 \mathrm{C}$ under $55^{\circ} \mathrm{C}$, and $\mathbf{e}, \mathbf{f} 1 \mathrm{C}$ under room temperature. $\mathbf{g}$ Schematic illustration on the morphologies of nanogaps in the cycled $\mathrm{O} 3 \mathrm{NaNi}_{0.4} \mathrm{Mnn}_{0.4} \mathrm{Co}_{0.2} \mathrm{O}_{2}$ as a function of cycling condition. 
temperature, we can see the propagation and widening of gaps (marked by yellow rectangles in Fig. 7c) as well as the new formation of high-density nanogaps (marked by yellow rectangles in Fig. 7d), which are similar to that observed during in situ TEM heating. This might be because of the increased extraction/ insertion kinetic of $\mathrm{Na}^{+}$at high temperatures. By switching to fast charging/discharging, the strain relaxation is aggressive and vigorous, thus leading to the formation of both large (marked by red rectangles in Fig. 7e) and high-density nanocracks (marked by red rectangles in Fig. 7f) with a curved incision. The relationship between strain relaxation and cycling temperature/rates is schematically illustrated in Fig. $7 \mathrm{~g}$. In addition, cracks in the macro scale were also observed in the cycled strained cathode under various conditions due to the relaxation of the native lattice strain (Supplementary Fig. 12).

In summary, through a combination of advanced diagnostics from material synthesis to cell failure, we have discovered the essential role of synthesis-induced native lattice strain in triggering the structure earthquake of sodium-layered oxide cathodes during cycling. The spontaneous relaxation of internal strain that exceeds the threshold limit is the fundamental origin of the abrupt degradation of sodium-layered oxide cathodes. Furthermore, we showed that such a process is not regulated by the charge cut-off voltage, but is strongly coupling with working temperature and charging/ discharging rates that can tailor the movement of $\mathrm{Na}^{+}$. Although surface coating or electrolytes modulation is effective in suppressing the irreversible phase transition and mitigating cathode-electrolyte parasitic reactions of sodium-layered oxide cathodes, these approaches cannot prevent the relaxation of intrinsic lattice strain. Our work indicates an urgent need to revisit the crystallographic structure of sodium /lithium layered oxide cathodes such as strain, oxygen vacancies, nanopores, domain boundaries, and other intrinsic defects, and to understand how they affect common battery phenomenon such as capacity fade and voltage decay/hysteresis. Our work also indicates that a rational strain management during cycling of sodium/lithium layered cathodes is required to maximize cycle life.

\begin{abstract}
Methods
Material synthesis. The $\mathrm{Ni}_{0.4} \mathrm{Mn}_{0.4} \mathrm{Co}_{0.2}(\mathrm{OH})_{2}$ precursor was synthesized through a co-precipitation method. The transition metal sulfate solution ( $\mathrm{Ni:Mn}: \mathrm{Co}=0.4: 0.4: 0.2$ in molar ratio) with a concentration of $2 \mathrm{~mol} / \mathrm{L}$ was fed into a continuously stirred tank reactor $(4 \mathrm{~L})$ under $\mathrm{N}_{2}$ protection. Concentrations of $4 \mathrm{~mol} / \mathrm{L} \mathrm{NaOH}$ and $5 \mathrm{~mol} / \mathrm{L}$ $\mathrm{NH}_{3} \cdot \mathrm{H}_{2} \mathrm{O}$ were also fed into the tank, respectively. The $\mathrm{pH}$ value was controlled at 10.8 during the co-precipitation process by adjusting the $\mathrm{NaOH}$ feeding rate ${ }^{69}$. The $\mathrm{Ni}_{0.4} \mathrm{Mn}_{0.4} \mathrm{Co}_{0.2}(\mathrm{OH})_{2}$ precursor was obtained by filtering and washing with deionized water followed by vacuum drying at $105^{\circ} \mathrm{C}$ overnight. To synthesize highly strained O3 $\mathrm{NaNi}_{0.4} \mathrm{Mn}_{0.4} \mathrm{Co}_{0.2} \mathrm{O}_{2}, \mathrm{Ni}_{0.4} \mathrm{Mn}_{0.4} \mathrm{Co}_{0.2}(\mathrm{OH})_{2}$ precursor and $\mathrm{NaOH}$ were mixed with a molar ratio of 1:1.05 using a rotary mixer. The mixture powder was then pressed into a pellet and heated to $850^{\circ} \mathrm{C}$ for $24 \mathrm{~h}$ with a heating rate of $3{ }^{\circ} \mathrm{C} / \mathrm{min}$ under an air atmosphere. The sample was then quenched from $850^{\circ} \mathrm{C}$ to room temperature in air and stored inside a glovebox for further characterization. As a comparison, the $\mathrm{P} 1 / \mathrm{P} 2 / \mathrm{O} 3 \mathrm{NaNi}_{0.4} \mathrm{Mn}_{0.4} \mathrm{Co}_{0.2} \mathrm{O}_{2}$ was synthesized by naturally cooling from $850^{\circ} \mathrm{C}$ to room temperature.
\end{abstract}

Electrochemical characterization. The electrode was made by spreading a mixture of 80 wt.\% active material, 10 wt.\% C45 and 10 wt.\% PVDF (8 wt.\% in NMP) onto Aluminum foil. The active material loading was controlled at around $3.5 \mathrm{mg} /$ $\mathrm{cm}^{2}$. The cycling performance of highly strained $\mathrm{O} 3 \mathrm{NaNi}_{0.4} \mathrm{Mn}_{0.4} \mathrm{Co}_{0.2} \mathrm{O}_{2}$ cathode was evaluated by assembling them into coin cells with $\mathrm{Na}$ metal as referenced and a counter electrode inside an Argonne-filled glovebox $\left(\mathrm{H}_{2} \mathrm{O} / \mathrm{O}_{2}:<0.5 \mathrm{ppm}\right)$. The electrolyte was $1 \mathrm{~mol} / \mathrm{L} \mathrm{NaPF}_{6}$ in propylene carbonate with $2 \mathrm{vol} \%$ fluoroethylene carbonate additive, and the separator was glass fiber (grade GF/F Glass Microfiber Filter Binder Free, circle, $125 \mathrm{~mm}$ ). The coin cells were then tested using MACCOR cycler under different voltage window $(2.0-4.4 \mathrm{~V}$ and $2.0-3.8 \mathrm{~V})$ at different charge/discharge rates and temperatures. These cycled cells were further harvested for ex-situ SEM and TEM analysis. The parasitic reactions of O3 $\mathrm{NaNi}_{0.4} \mathrm{Mn}_{0.4^{-}}$ $\mathrm{Co}_{0.2} \mathrm{O}_{2}$ cathode were measured by a home-built high-precision leakage current measurement system ${ }^{26}$. The $\mathrm{Na} / \mathrm{NaNi}_{0.4} \mathrm{Mn}_{0.4} \mathrm{Co}_{0,2} \mathrm{O}_{2}$ cell was under formation for two cycles and then charged to different voltages and held at each specific potential for $40 \mathrm{~h}$ using a Keithley 2401 source meter. During these processes, the leakage currents were monitored and measured. The measured leakage current was proportional to the reaction rate of parasitic (side) reactions between the working electrode and the electrolyte.

In situ SXRD during heating and cycling. The in situ SXRD experiments were conducted at 11-ID-C of Advanced Photon Sources of Argonne National Laboratory with a wavelength of $0.117418 \AA$. For the in situ synthesis, the mixture of $\mathrm{Ni}_{0.4} \mathrm{Mn}_{0.4} \mathrm{Co}_{0.2}(\mathrm{OH})_{2}$ precursor and $\mathrm{NaOH}$ was pressed into a $7 \mathrm{~mm}$ diameter pellet and loaded into a LINKAM TS- 1500 furnace and then heated to $875^{\circ} \mathrm{C}$ at a heating rate of $3{ }^{\circ} \mathrm{C} / \mathrm{min}$ and then held at $875^{\circ} \mathrm{C}$ for $7 \mathrm{~h}$ followed by quenching to room temperature. For in situ charge/discharge, coin cells with a hole on both top and bottom were used. The holes were sealed with Kapton tape after assembling the $\mathrm{Na} / \mathrm{NaNi}_{0.4} \mathrm{Mn}_{0.4} \mathrm{Co}_{0.2} \mathrm{O}_{2}$ coin cells, which were charged/discharged within $2.0-3.8 \mathrm{~V}$ and $2.0-4.4 \mathrm{~V}$ at $18 \mathrm{~mA} / \mathrm{g}$, respectively. SXRD patterns were collected during in situ heating and in situ cycling processes.

XANES during charge/discharge. The in situ Ni K-edge XANES experiment was conducted in transmission mode at 20-BM of Advanced Photon Sources of Argonne National Laboratory. The incident beam was monochromatized by using a $\mathrm{Si}(111)$ fixed-exit, double-crystal monochromator. During the in situ experiment, the $\mathrm{Na} /$ $\mathrm{NaNi}_{0.4} \mathrm{Mn}_{0.4} \mathrm{Co}_{0.2} \mathrm{O}_{2}$ cell was charged/discharged with a constant current density of $25 \mathrm{~mA} / \mathrm{g}$ between 2.0 and $4.4 \mathrm{~V}$ using a MACCOR cycler. Ex-situ Ni K-edge, Co Kedge, and Mn K-edge XANES of strained O3 $\mathrm{NaNi}_{0.4} \mathrm{Mn}_{0.4} \mathrm{Co}_{0.2} \mathrm{O}_{2}$ cathodes under different charge/discharge states were also conducted at 20-BM of Advanced Photon Sources of Argonne National Laboratory. The cycled electrodes were disassembled and rinsed with dimethyl carbonate (DMC, Sigma Aldrich, $>99 \%$, anhydrous) to remove electrolyte residue, and then sealed with Kapton tape for measurement.

Structure characterization. The TGA analysis was conducted using STA 449 F3 instrument to measure the weight loss of the $\mathrm{Ni}_{0.4} \mathrm{Mn}_{0.4} \mathrm{Co}_{0.2}(\mathrm{OH})_{2} / \mathrm{NaOH}$ mixture during heating from room temperature to $900{ }^{\circ} \mathrm{C}$ with a heating rate of $10{ }^{\circ} \mathrm{C} / \mathrm{min}$ under the atmosphere of air. The morphologies of the $\mathrm{NaNi}_{0.4} \mathrm{Mn}_{0.4} \mathrm{Co}_{0.2} \mathrm{O}_{2}$ were characterized by scanning electron microscopy (JEOL 7100F) and TEM (JEOL 2100F). The Zeiss NVision 40 focused ion beam-scanning electron microscopy dual-beam system was used to prepare a cross-section TEM specimen through a standard lift-out procedure. The HAADF imaging and elemental mapping were conducted at FEI Talos F200X (S)TEM equipped with a SuperX energy-dispersive $\mathrm{X}$-ray spectrometer. The In situ heating TEM experiments during heating of a 3.8 V-charged $\mathrm{NaNi}_{0.4} \mathrm{Mn}_{0.4} \mathrm{Co}_{0.2} \mathrm{O}_{2}$ electrode were conducted on JEOL $2100 \mathrm{~F}$ from room temperature to $250{ }^{\circ} \mathrm{C}$ by using a Gatan bulk heating holder. HREM was carried out on a FEI Titan 80-300 ST, equipped with a CEOS Cc/Cs image corrector and operated at $200 \mathrm{kV}$. C 1s XPS of slow-cooled layered oxide cathodes were conducted using a PHI 5000 VersaProbe II XPS Microprobe (Physical Electronics), with $\mathrm{Al} \mathrm{Ka}$ radiation ( $1486.6 \mathrm{eV}, 100 \mu \mathrm{m}$ diameter at focus, $25 \mathrm{~W}$ ), $\mathrm{Ar}^{+}$, and electron beam sample neutralization. The obtained spectra were calibrated using the $\mathrm{C}-\mathrm{C}$ peak at $284.8 \mathrm{eV}$ in the $\mathrm{C} 1 s$.

In situ DEMS. The in situ DEMS experiment was conducted in a custom-made system. The electrode was prepared by spreading a slurry consisting of $80 \mathrm{wt} . \%$ $\mathrm{NaNi}_{0.4} \mathrm{Mn}_{0.4} \mathrm{Co}_{0.2} \mathrm{O}_{2}, 10$ wt.\% PVDF binder, and 10 wt.\% C45 onto a $16-\mathrm{mm}$ diameter carbon paper and then dried (areal active material loading: $10 \mathrm{mg} / \mathrm{cm}^{2}$ ). We assembled a 2025-coin cell with a hole with a sodium metal anode and glass fiber separator, which was charging/discharging within $2.0-4.4 \mathrm{~V}$ at a current density of $30 \mathrm{~mA} / \mathrm{g}$. The carrier gas was pre-dehydrated helium $(99.999 \%)$ with a flow rate of $8 \mathrm{~mL} / \mathrm{min}$. The gas species generated during cycling were then passed through a cold trap (mixture of dry ice and ethanol at $-78.5^{\circ} \mathrm{C}$ and $1 \mathrm{~atm}$ ) to condense the electrolyte vapor before it was sent to the mass spectrometer (modified 5975C mass-selective detector, Agilent) for analysis.

Reporting summary. Further information on research design is available in the Nature Research Reporting Summary linked to this article.

\section{Data availability}

The data that support the findings of this study are available from the corresponding authors G.-L.X., Y.L., and K.A. upon reasonable request.

Received: 1 September 2021; Accepted: 6 January 2022; Published online: 27 January 2022

\section{References}

1. Li, J. et al. Structural origin of the high-voltage instability of lithium cobalt oxide. Nat. Nanotechnol. 16, 599-605 (2021).

2. $\mathrm{Xu}, \mathrm{G}$.-L. et al. Challenges and strategies to advance high-energy nickel-rich layered lithium transition metal oxide cathodes for harsh operation. Adv. Funct. Mater. 30, 2004748 (2020). 
3. Li, W., Erickson, E. M. \& Manthiram, A. High-nickel layered oxide cathodes for lithium-based automotive batteries. Nat. Energy 5, 26-34 (2020).

4. You, Y. \& Manthiram, A. Progress in high-voltage cathode materials for rechargeable sodium-ion batteries. Adv. Energy Mater. 8, 1701785 (2018).

5. Song, S. H. et al. High-voltage-driven surface structuring and electrochemical stabilization of $\mathrm{Ni}$-Rich layered cathode materials for Li rechargeable batteries. Adv. Energy Mater. 10, 2000521 (2020).

6. Mao, Y. et al. High-voltage charging-induced strain, heterogeneity, and microcracks in secondary particles of a nickel-rich layered cathode material. Adv. Funct. Mater. 29, 1900247 (2019).

7. House, R. A. et al. Superstructure control of first-cycle voltage hysteresis in oxygen-redox cathodes. Nature 577, 502-508 (2020).

8. Wang, Y. et al. Pillar-beam structures prevent layered cathode materials from destructive phase transitions. Nat. Commun. 12, 13 (2021)

9. Xu, C., Reeves, P. J., Jacquet, Q. \& Grey, C. P. Phase behavior during electrochemical cycling of Ni-Rich cathode materials for Li-ion batteries. $A d v$. Energy Mater. 11, 2003404 (2021).

10. Xu, C. et al. Bulk fatigue induced by surface reconstruction in layered $\mathrm{Ni}$-rich cathodes for Li-ion batteries. Nat. Mater. 20, 84-92 (2021).

11. Lin, F. et al. Surface reconstruction and chemical evolution of stoichiometric layered cathode materials for lithium-ion batteries. Nat. Commun. 5, 3529 (2014).

12. Xu, G.-L. et al. Challenges in developing electrodes, electrolytes, and diagnostics tools to understand and advance sodium-ion batteries. Adv Energy Mater. 8, 1702403 (2018).

13. Yabuuchi, N., Kubota, K., Dahbi, M. \& Komaba, S. Research development on sodium-ion batteries. Chem. Rev. 114, 11636-11682 (2014).

14. Wang, P.-F. et al. Suppressing the $\mathrm{P} 2-\mathrm{O} 2$ phase transition of $\mathrm{Na}_{0.67} \mathrm{Mn}_{0.67}$ $\mathrm{Ni}_{0.33} \mathrm{O}_{2}$ by magnesium substitution for improved sodium-ion batteries. Angew. Chem. Int. Ed. 55, 7445-7449 (2016).

15. Somerville, J. W. et al. Nature of the "Z"-phase in layered Na-ion battery cathodes. Energy Environ. Sci. 12, 2223-2232 (2019).

16. Jin, T. et al. Realizing complete solid-solution reaction in high sodium content P2-type cathode for high-performance sodium-ion batteries. Angew. Chem. Int. Ed. 59, 14511-14516 (2020).

17. Yu, T.-Y., Ryu, H.-H., Han, G. \& Sun, Y.-K. Understanding the capacity fading mechanisms of O3-Type $\mathrm{Na}\left[\mathrm{Ni}_{0.5} \mathrm{Mn}_{0.5}\right] \mathrm{O}_{2}$ cathode for sodium-ion batteries. Adv. Energy Mater. 10, 2001609 (2020).

18. Wang, K., Yan, P. \& Sui, M. Phase transition induced cracking plaguing layered cathode for sodium-ion battery. Nano Energy 54, 148-155 (2018).

19. Yan, P. et al. Intragranular cracking as a critical barrier for high-voltage usage of layer-structured cathode for lithium-ion batteries. Nat. Commun. 8, 14101 (2017).

20. Yan, P. et al. Coupling of electrochemically triggered thermal and mechanical effects to aggravate failure in a layered cathode. Nat. Commun. 9, 2437 (2018).

21. You, Y. et al. Insights into the improved high-voltage performance of $\mathrm{Li}-$ incorporated layered oxide cathodes for sodium-ion batteries. Chem. 4, 2124-2139 (2018).

22. Yang, $\mathrm{L}$. et al. Lithium-doping stabilized high-performance $\mathrm{P} 2-\mathrm{Na}_{0.66} \mathrm{Li}_{0.18} \mathrm{Fe}_{0.12}$ $\mathrm{Mn}_{0.7} \mathrm{O}_{2}$ cathode for sodium ion batteries. J. Am. Chem. Soc. 141, 6680-6689 (2019).

23. Singh, G. et al. High voltage Mg-doped $\mathrm{Na}_{0.67} \mathrm{Ni}_{0.3-\mathrm{x}} \mathrm{Mg}_{\mathrm{x}} \mathrm{Mn}_{0.7} \mathrm{O}_{2}(\mathrm{x}=0.05$, $0.1)$ Na-Ion cathodes with enhanced stability and rate capability. Chem. Mater. 28, 5087-5094 (2016).

24. Zhang, J.-N. et al. Trace doping of multiple elements enables stable battery cycling of $\mathrm{LiCoO}_{2}$ at $4.6 \mathrm{~V}$. Nat. Energy 4, 594-603 (2019).

25. Liu, Q. et al. Approaching the capacity limit of lithium cobalt oxide in lithium ion batteries via lanthanum and aluminium doping. Nat. Energy 3, 936-943 (2018).

26. Zeng, $\mathrm{X}$. et al. Kinetic study of parasitic reactions in lithium-ion batteries: a case study on $\mathrm{LiNi}_{0.6} \mathrm{Mn}_{0.2} \mathrm{Co}_{0.2} \mathrm{O}_{2}$. ACS Appl. Mater. Interfaces 8, 3446-3451 (2016).

27. Goodenough, J. B. \& Kim, Y. Challenges for rechargeable Li batteries. Chem. Mater. 22, 587-603 (2010).

28. Lee, E. et al. New insights into the performance degradation of Fe-based layered oxides in sodium-ion batteries: instability of $\mathrm{Fe}^{3+} / \mathrm{Fe}^{4+}$ redox in $\alpha$ $\mathrm{NaFeO}_{2}$. Chem. Mater. 27, 6755-6764 (2015).

29. $\mathrm{Mu}, \mathrm{L}$. et al. Deciphering the cathode-electrolyte interfacial chemistry in sodium layered cathode materials. Adv. Energy Mater. 8, 1801975 (2018).

30. Xu, G.-L. et al. Building ultraconformal protective layers on both secondary and primary particles of layered lithium transition metal oxide cathodes. Nat. Energy 4, 484-494 (2019).

31. Yan, P. et al. Tailoring grain boundary structures and chemistry of Ni-rich layered cathodes for enhanced cycle stability of lithium-ion batteries. Nat. Energy 3, 600-605 (2018).

32. Yoon, M. et al. Reactive boride infusion stabilizes Ni-rich cathodes for lithium-ion batteries. Nat. Energy 6, 362-371 (2021).
33. Kaliyappan, K. et al. Constructing safe and durable high-voltage P2 layered cathodes for sodium ion batteries enabled by molecular layer deposition of alucone. Adv. Funct. Mater. 30, 1910251 (2020).

34. Su, C.-C. et al. Oxidatively stable fluorinated sulfone electrolytes for high voltage high energy lithium-ion batteries. Energy Environ. Sci. 10, 900-904 (2017).

35. Jiao, S. et al. Stable cycling of high-voltage lithium metal batteries in ether electrolytes. Nat. Energy 3, 739-746 (2018).

36. Wang, J. et al. Superconcentrated electrolytes for a high-voltage lithium-ion battery. Nat. Commun. 7, 12032 (2016).

37. Bianchini, $M$. et al. The interplay between thermodynamics and kinetics in the solid-state synthesis of layered oxides. Nat. Mater. 19, 1088-1095 (2020).

38. $\mathrm{Li}$, Y. et al. Synthesis of full concentration gradient cathode studied by high energy X-ray diffraction. Nano Energy 19, 522-531 (2016).

39. Zhang, M.-J. et al. Cooling induced surface reconstruction during synthesis of high-Ni layered oxides. Adv. Energy Mater. 9, 1901915 (2019).

40. Duan, Y. et al. Insights into Li/Ni ordering and surface reconstruction during synthesis of Ni-rich layered oxides. J. Mater. Chem. A 7, 513-519 (2019).

41. Wang, D. et al. Synthetic control of kinetic reaction pathway and cationic ordering in high-Ni layered oxide cathodes. Adv. Mater. 29, 1606715 (2017).

42. Xu, G.-L. et al. Insights into the structural effects of layered cathode materials for high voltage sodium-ion batteries. Energy Environ. Sci. 10, 1677-1693 (2017).

43. Niu, Y.-B., Yin, Y.-X. \& Guo, Y.-G. Nonaqueous sodium-ion full cells: status, strategies, and prospects. Small 15, 1900233 (2019).

44. Xiong, X. C., Chen, B., Huang, M. X., Wang, J. F. \& Wang, L. The effect of morphology on the stability of retained austenite in a quenched and partitioned steel. Scr. Mater. 68, 321-324 (2013).

45. Burke, S. \& Whitacre, J. F. How synthetic quench rate and composition affect the performance of lithium nickel manganese oxide cathode materials. $J$. Electrochem. Soc. 167, 160518 (2020).

46. Nomura, F. et al. The effect of cooling process on the structure and charge/ discharge capacities of Li-rich solid-solution layered oxide cathode materials for the Li-ion battery. Rsc. Adv. 11, 1715-1728 (2021).

47. Jung, R., Metzger, M., Maglia, F., Stinner, C. \& Gasteiger, H. A. Chemical versus electrochemical electrolyte oxidation on NMC111, NMC622, NMC811, LNMO, and conductive carbon. J. Phys. Chem. Lett. 8, 4820-4825 (2017).

48. Wandt, J., Freiberg, A. T. S., Ogrodnik, A. \& Gasteiger, H. A. Singlet oxygen evolution from layered transition metal oxide cathode materials and its implications for lithium-ion batteries. Mater. Today 21, 825-833 (2018)

49. Jung, R., Strobl, P., Maglia, F., Stinner, C. \& Gasteiger, H. A. Temperature dependence of oxygen release from $\mathrm{LiNi}_{0.6} \mathrm{Mn}_{0.2} \mathrm{Co}_{02} \mathrm{O}_{2}$ (NMC622) cathode materials for Li-Ion batteries. J. Electrochem. Soc. 165, A2869-A2879 (2018).

50. Freiberg, A. T. S., Roos, M. K., Wandt, J., de Vivie-Riedle, R. \& Gasteiger, H. A. Singlet oxygen reactivity with carbonate solvents used for Li-ion battery electrolytes. J. Phys. Chem. A 122, 8828-8839 (2018).

51. Sathiya, M., Hemalatha, K., Ramesha, K., Tarascon, J. M. \& Prakash, A. S Synthesis, structure, and electrochemical properties of the layered sodium insertion cathode material: $\mathrm{NaNi}_{1 / 3} \mathrm{Mn}_{1 / 3} \mathrm{Co}_{1 / 3} \mathrm{O}_{2}$. Chem. Mater. 24, 1846-1853 (2012)

52. Komaba, S. et al. Study on the reversible electrode reaction of $\mathrm{Na}_{1-\mathrm{x}} \mathrm{Ni}_{0.5} \mathrm{Mn}_{0.5} \mathrm{O}_{2}$ for a rechargeable sodium-ion battery. Inorg. Chem. $\mathbf{5 1}$, 6211-6220 (2012).

53. Wang, P.-F. et al. Ti-Substituted $\mathrm{NaNi}_{0.5} \mathrm{Mn}_{0.5-\mathrm{x}} \mathrm{Ti}_{\mathrm{x}} \mathrm{O}_{2}$ cathodes with reversible $\mathrm{O} 3-\mathrm{P} 3$ phase transition for high-performance sodium-ion batteries. $A d v$. Mater. 29, 1700210 (2017).

54. Song, J. et al. Controlling surface phase transition and chemical reactivity of O3-layered metal oxide cathodes for high-performance Na-ion batteries. ACS Energy Lett. 5, 1718-1725 (2020).

55. Ito, A. et al. Cyclic deterioration and its improvement for Li-rich layered cathode material $\mathrm{Li}\left[\mathrm{Ni}_{0.17} \mathrm{Li}_{0.2} \mathrm{Co}_{0.07} \mathrm{Mn}_{0.56} \mathrm{O}_{2}\right.$. J. Power Sources 195, $567-573$ (2010).

56. Lee, J. et al. Unlocking the potential of cation-disordered oxides for rechargeable lithium batteries. Science 343, 519-522 (2014).

57. Liu, W. et al. Nickel-rich layered lithium transition-metal oxide for highenergy lithium-ion batteries. Angew. Chem. Int. Ed. 54, 4440-4457 (2015).

58. Talaie, E., Kim, S. Y., Chen, N. \& Nazar, L. F. Structural Evolution and redox processes involved in the electrochemical cycling of $\mathrm{P} 2-\mathrm{Na}_{0.67}\left[\mathrm{Mn}_{0.66} \mathrm{Fe}_{0.20} \mathrm{Cu}_{0.14}\right]$ $\mathrm{O}_{2}$. Chem. Mater. 29, 6684-6697 (2017).

59. Talaie, E., Duffort, V., Smith, H. L., Fultz, B. \& Nazar, L. F. Structure of the high voltage phase of layered $\mathrm{P} 2-\mathrm{Na}_{2 / 3-\mathrm{z}}\left[\mathrm{Mn}_{1 / 2} \mathrm{Fe}_{1 / 2}\right] \mathrm{O}_{2}$ and the positive effect of Ni substitution on its stability. Energy Environ. Sci. 8, 2512-2523 (2015).

60. Zhang, H. et al. Rock-salt growth-induced (003) cracking in a layered positive electrode for Li-Ion batteries. ACS Energy Lett. 2, 2607-2615 (2017).

61. $\mathrm{Li}, \mathrm{S}$. et al. Surface-to-bulk redox coupling through thermally driven $\mathrm{Li}$ redistribution in Li- and Mn-rich layered cathode materials. J. Am. Chem. Soc. 141, 12079-12086 (2019). 
62. Ko, D.-S. et al. Degradation of high-nickel-layered oxide cathodes from surface to bulk: a comprehensive structural, chemical, and electrical analysis. Adv. Energy Mater. 10, 2001035 (2020).

63. Jiang, Y. et al. Atomistic mechanism of cracking degradation at twin boundary of $\mathrm{LiCoO}_{2}$. Nano Energy 78, 105364 (2020).

64. Lee, S.-Y. et al. Revisiting primary particles in layered lithium transition-metal oxides and their impact on structural degradation. Adv. Sci. 6, 1800843 (2019).

65. Li, S. et al. Direct observation of defect-aided structural evolution in a nickelrich layered cathode. Angew. Chem. Int. Ed. 59, 22092-22099 (2020).

66. Ahmed, S. et al. Understanding the formation of antiphase boundaries in layered oxide cathode materials and their evolution upon electrochemical cycling. Matter 4, 3953-3966 (2021).

67. Ahmed, $\mathrm{S}$. et al. The role of intragranular nanopores in capacity fade of nickelrich layered $\mathrm{Li}\left(\mathrm{Ni}_{1-\mathrm{x}-\mathrm{y}} \mathrm{Co}_{\mathrm{x}} \mathrm{Mn}_{\mathrm{y}}\right) \mathrm{O}_{2}$ cathode materials. ACS Nano 13, 10694-10704 (2019).

68. $\mathrm{Xu}, \mathrm{Z}$. et al. Charging reactions promoted by geometrically necessary dislocations in battery materials revealed by in situ single-particle synchrotron measurements. Adv. Mater. 32, 2003417 (2020).

69. Barai, P., Feng, Z., Kondo, H. \& Srinivasan, V. Multiscale computational model for particle size evolution during coprecipitation of Li-ion battery cathode precursors. J. Phys. Chem. B 123, 3291-3303 (2019).

\section{Acknowledgements}

Research at Argonne National Laboratory was funded by the U.S. Department of Energy (DOE) Vehicle Technologies Office. Support from Tien Duong of DOE's Vehicle Technologies Office is gratefully acknowledged. Use of the Advanced Photon Source and Centre for Nanoscale Materials was supported by the U.S. Department of Energy, Office of Science, and Office of Basic Energy Sciences, under Contract No. DEAC02-06CH11357.

\section{Author contributions}

G.-L.X. conceived the idea and designed the experiments. G.-L.X., X.L., Y.R., and Z.C. performed all the in situ SXRD experiments and processed the data. Y.L., X.Z., and G.L.X. performed the electron microscopy characterization and data analysis. G.-L.X. synthesized the materials and performed the electrochemical characterization. G.-L.X. I.H., and C.-J.S. performed in situ XANES experiments and data analysis. C.Z. and A.D. prepared the samples for ex-situ XAS measurement. Z.Y. conducted the XPS measurement. G.-L.X. wrote and revised the manuscript. G.-L.X. and K.A. managed the project. All authors contributed to discussions and paper revisions.

\section{Competing interests}

The authors declare no competing interests.

\section{Additional information}

Supplementary information The online version contains supplementary material available at https://doi.org/10.1038/s41467-022-28052-x.

Correspondence and requests for materials should be addressed to Gui-Liang Xu, Yuzi Liu or Khalil Amine.

Peer review information Nature Communications thanks Nicholas S. Grundish and the other, anonymous, reviewer for their contribution to the peer review of this work. Peer reviewer reports are available.

Reprints and permission information is available at http://www.nature.com/reprints

Publisher's note Springer Nature remains neutral with regard to jurisdictional claims in published maps and institutional affiliations.

cc (i) Open Access This article is licensed under a Creative Commons Attribution 4.0 International License, which permits use, sharing, adaptation, distribution and reproduction in any medium or format, as long as you give appropriate credit to the original author(s) and the source, provide a link to the Creative Commons license, and indicate if changes were made. The images or other third party material in this article are included in the article's Creative Commons license, unless indicated otherwise in a credit line to the material. If material is not included in the article's Creative Commons license and your intended use is not permitted by statutory regulation or exceeds the permitted use, you will need to obtain permission directly from the copyright holder. To view a copy of this license, visit http://creativecommons.org/ licenses/by/4.0/.

(c) UChicago Argonne, LLC, Operator of Argonne National Laboratory. 2022 